\title{
Cone Photoreceptor Regeneration in Adult Fish Retina: Phenotypic Determination and Mosaic Pattern Formation
}

\author{
David A. Cameron and Stephen S. Easter, Jr. \\ Department of Biology, University of Michigan, Ann Arbor, Michigan 48109-1048
}

\begin{abstract}
The retina of anamniotes (fish and amphibia), unlike the CNS of most vertebrates, can regenerate neurons following injury. Using the highly ordered mosaic of single and double cones in the retina of the adult green sunfish (Lepomis cyanellus) as our model system, we examined the events that followed the surgical excision of a small patch of central retina. After surgery there was a transient elevation in the number, and a change in the distribution, of proliferative cells within the retina. The wound was filled in two ways: a proliferative regeneration of new retina and a nonproliferative movement of the wound boundaries toward the center of the lesion. The nonproliferative movement stretched the surrounding, intact retina. In stretched retina the basic pattern of the cone mosaic was maintained, but it was augmented by new cones, even though cones are not normally generated in intact central retina. The stretch itself likely triggered the anomalous cone production. The new and preexisting cones in stretched retina had their morphological phenotypes influenced by mutual contact, often resulting in atypical morphologies (triple and quadruple cones). In the center of the lesioned area, the regenerated cone mosaic was disordered, had a higher than normal cone density, and contained atypical morphologies. The presence of outer segments and synaptic pedicles suggested that the new cones in regenerated and stretched retina were functional. We interpret these results to mean (1) a stretch-induced decrease in cell density can trigger a compensatory, adaptive neurogenesis, (2) cone morphological phenotypes in fish retina are plastic throughout life, and are influenced by cone-cone contacts, (3) the mechanisms that spatially regulate cone production during normal growth are disrupted during regeneration.
\end{abstract}

[Key words: regeneration, retina, neurogenesis, photoreceptors, fish, cones]

The CNS of anamniotes (fish and amphibia) has remarkable powers of repair and regeneration, and one of the most remarkable is their ability to regenerate whole new tissue. This has been best documented in the neural retina, first by Matthey

\footnotetext{
Received Aug. 5, 1994; revised Sept. 14, 1994; accepted Sept. 28, 1994.

We thank Celesté Malinoski for technical assistance, Dr. Kathy Tosney for the cryosection protocol, and Drs. Laurel Carney, Grant Mastick, Charlotte Mistretta, and Pamela Raymond for their comments on the manuscript. This work was supported by NIH Grants EY-00168 (S.S.E.) and F32 EY-06469 (D.A.C.), and a Sokol Postdoctoral Award (D.A.C.).

Correspondence should be addressed David A. Cameron, Department of Biomedical Engineering, Boston University, 44 Cummington Street, Boston, MA 02215-2407.

Copyright $(\mathcal{C} 1995$ Society for Neuroscience $0270-6474 / 95 / 152255-17 \$ 05.00 / 0$
}

(1926), who transplanted whole eyes of urodele amphibians, and showed that the restoration of vision occurred after a complete degeneration, then regeneration, of the neural retina. Sperry (1949) showed that fish retina could do the same, and Wolburg and Raymond and their collaborators (e.g., Maier and Wolburg, 1979; Raymond et al., 1988) have extended this work.

Regeneration of fish neural retina also occurs following the surgical removal of a small patch. Hitchcock et al. (1992) demonstrated that an excised patch is filled epimorphically, as a rcsult of mitotic activity in a population of proliferative cells that forms along the perimeter of the wound. This wound blastema resembles the proliferative neuroepithelium (the marginal germinal zone) that encircles the retina (Hitchcock et al., 1992; MacDonald et al., 1994), but the two proliferative zones are oriented differently. As cells in the marginal germinal zone proliferate, their postmitotic daughter cells remain central to the retinal margin, and the proliferative stem cells are displaced centrifugally as part of an ever-increasing retinal perimeter. In contrast, the stem cells of the wound blastema are displaced centripetally, toward the center of the wound, and their postmitotic daughter cells remain outside the wound perimeter to form the regenerated neural retina.

Studies of epithelial wound healing have described a different, nonproliferative mechanism for filling in the wound that may affect neural regeneration in the fish retina. When a patch of embryonic chick skin is surgically removed, the perimeter of the wound is partially reduced by a purse-string-like closure caused by the contraction of an actin belt that rapidly forms around the lesion (Martin and Lewis, 1992). If the filling-in of a retinal wound involves a similar, nonproliferative inward spread of the wound boundaries, then the intact retina surrounding the lesion must be stretched. This stretch would reduce the planimetric density of the retinal cells in the area surrounding the wound, because the same number of cells would be spread over a greater area. Such a reduction would be of interest because the planimetric density of retinal cells is functionally important, particularly in the photoreceptor layer, where rods and cones cover the retinal lawn to maximize the capture of incident light. If a surgical lesion causes the retina to stretch suddenly (as distinct from the slow stretch that accompanies normal retinal growth; Ali, 1964; Johns and Easter, 1977), then perhaps new cells are generated to compensate for the reduction in density. Interstitial insertion of new neurons into an intact nervous system is intrinsically interesting, and may have long-range clinical importance.

This article studies the sequels to removal of a small patch of adult green sunfish retina, with particular attention to the region surrounding the wound. In this endeavor we have taken advantage of the very orderly mosaic of cone photoreceptors (Cam- 
a

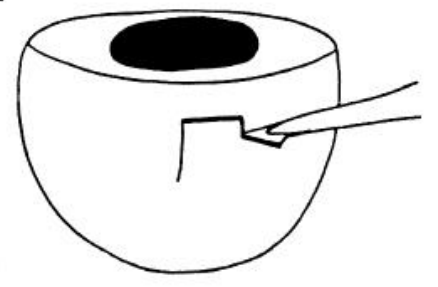

b

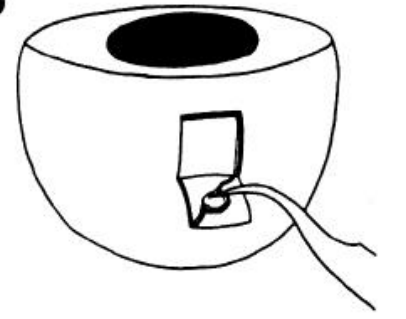

C

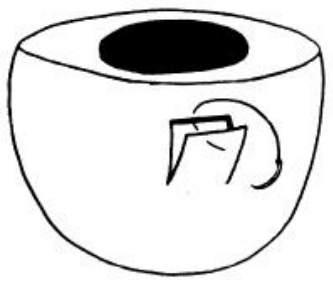

d

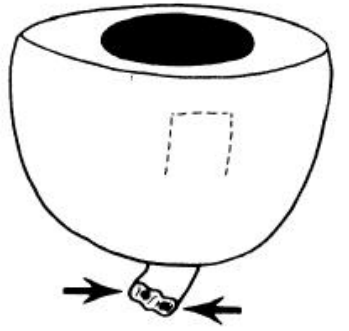

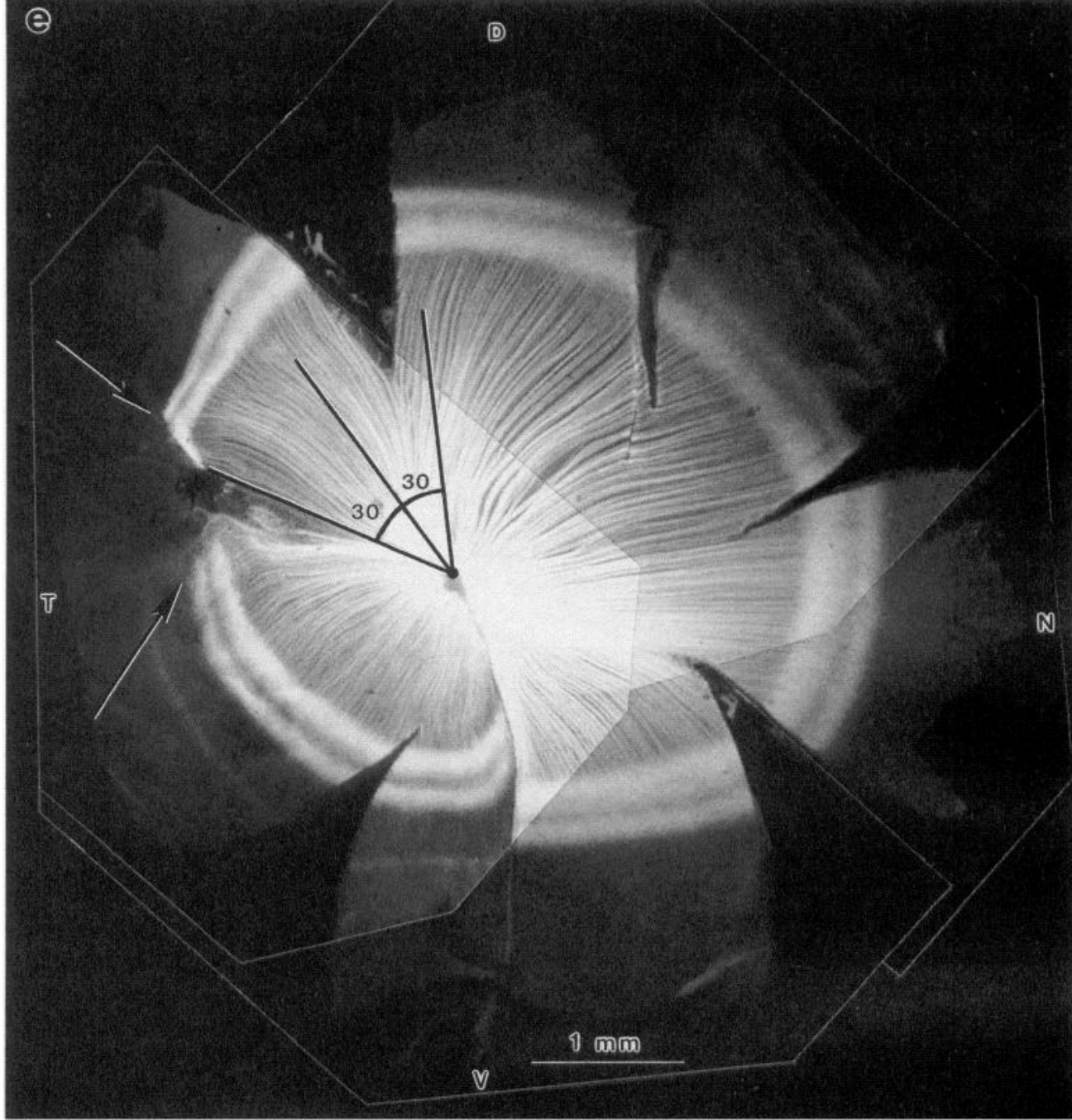

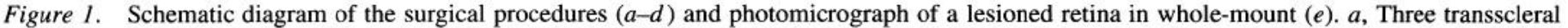

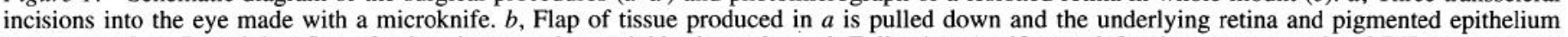

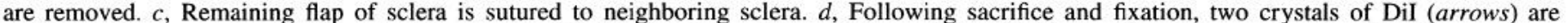

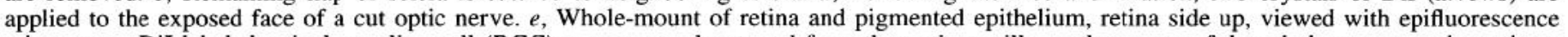

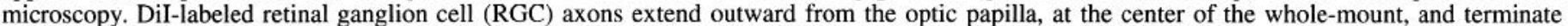

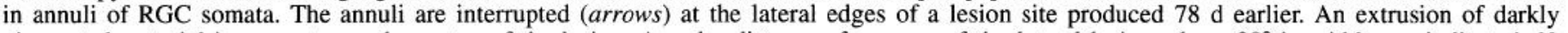

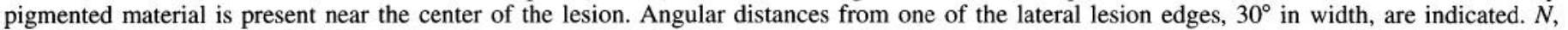
nasal; $D$, dorsal; $T$, temporal; $V$ ventral.

eron and Easter, 1993). We report that the intact retina surrounding a wound is stretched by a nonproliferative spread into the lesion. Within stretched retina, the cone mosaic is augmented by the interstitial addition of new cone cells, a neural cell type that is not normally generated in central, intact retina. The assembly of the cone mosaic, the determination of cone phenotype, and the replacement of neurons in the adult CNS are discussed.

\section{Materials and Methods}

Adult green sunfish (Lepomis cyanellus, $n=32$ ) were purchased from Fender's Fish Hatchery and Llama Farm (Baltic, OH). Animal husbandry, anesthesia, and euthanasia techniques were as described previously (Cameron and Easter, 1993). Fully light adapted fish were used in all procedures.

Retinal surgery. Small transscleral excisions were made of dorsotemporal retina and pigmented epithelium of one eye (Hitchcock et al. 1992); the other eye was unoperated $(n=25)$. The excisions were roughly square and approximately $2-4 \mathrm{~mm}^{2}$ in area (Fig. $1 a-d$ ). These fish survived for $2-430 \mathrm{~d}$. In other fish $(n=7)$, only a single transscleral slit incision was made through one retina, and the other was unoperated. These fish survived 8,14 , or $45 \mathrm{~d}$.

Cone mosaic analysis: whole-mounts. Following sacrifice, both eyes were enucleated and the corneas and lenses were removed. The resulting eye cups were fixed by immersion in $4 \%$ paraformaldehyde in $0.05 \mathrm{M}$ $\mathrm{PO}_{4}$ buffer overnight. One or more small pellets of the fluorescent carbocyanine dye DiI (1,1'-dioctadecyl-3,3,3',3'-tetramethylindocarbocyanine perchlorate; Molecular Probes, Eugene, OR; Honig and Hume, 1986; Godement et al., 1987) were embedded within the cut face of the optic nerve $(n=13)$, and the eye cups were incubated in fixative at $45^{\circ} \mathrm{C}$ for $5 \mathrm{~d}$. DiI was incorporated into retinal ganglion cell (RGC) axonal membranes local to the pellet, and retrogradely labeled annuli of RGC somata and dendrites (Easter, 1992; Cameron and Easter, 1993), and one of these annuli generally intersected the lesion site or lay peripheral to it. Retinal whole-mounts were made with the pigment epithelium side down, cover slipped with $50 \%$ glycerol, $50 \% \mathrm{PO}_{4}$ buffer, and viewed with epifluorescence microscopy. Cone mosaics were visualized by focusing through the whole-mounts.

The lateral edges of the lesions were visualized as gaps within the annuli of DiI-labeled RGC somata and dendritic fields (Fig. 1e). Such a gap existed even after long survivals, indicating that the regenerated 
axons from those somata inside the lesion and peripheral to it did not rejoin the fascicles they occupied prior to the surgery. This confirmed earlier work that demonstrated disorderly axonal regeneration (Bernhardt and Easter, 1988). For purpose of analysis, retina lateral to these edges was divided into wedge-shaped bins $30^{\circ}$ in width, centered on the dorsal-most point of the optic papilla (Fig. 1e). All quantitative comparisons of operated and unoperated eyes were made between corresponding retinal locations in the same individual fish.

Cone mosaic analysis: electron microscopy. Eyes were prepared for electron microscopy using standard techniques $(n=3)$. Briefly, anesthetized fish were perfused with fixative $(3.2 \%$ glutaraldehyde, $3.75 \%$ sucrose, $1 \mathrm{mM} \mathrm{CaCl}_{2}$ in $0.05 \mathrm{M}^{\mathrm{m}}$ cacodylate [CACO] buffer), the cornea and lens were removed from both eyes, and the eye cups were further fixed by immersion for $4 \mathrm{hr}$. Following removal of the sclera and choroid, the eye cups were washed repeatedly with $3.75 \%$ sucrose, $1 \mathrm{~mm}$ $\mathrm{CaCl}_{2}, 0.5 \mathrm{M}$ CACO buffer over $3 \mathrm{~d}$, and postfixed for $2 \mathrm{hr}$ in $1 \%$ osmium tetroxide/potassium ferricyanide in CACO buffer. After several rinses in $\mathrm{dH}_{2} \mathrm{O}$, the eye cups were washed in $0.05 \mathrm{M}$ maleate buffer for $2 \mathrm{hr}$. Eye cups were then stained en bloc with $2 \%$ uranyl acetate, 0.05 M maleate buffer (which was filtered at $0.22 \mu \mathrm{m}$ ) overnight at $4^{\circ} \mathrm{C}$. The material was then washed in $0.05 \mathrm{M}$ maleate buffer, serially dehydrated in ethanols, and infiltrated sequentially in $2: 1,1: 1$, and $1: 2$ ratios of fresh propylene oxide/Epon, with overnight storage in the 1:2 solution. The next day, the propylene oxide was evaporated away, and the tissue was transferred to fresh $100 \%$ Epon for $4 \mathrm{hr}$, and embedded. Tangential sections were cut through the retina at $60-90 \mathrm{~nm}$ thickness, at the level of the cones. Sections were placed upon either open copper or Formvar film grids, and examined with a Philips 300 transmission electron microscope. One retina was examined in a continuous series of 380 tangential ultrathin sections, extending from the cone ellipsoids through to the synaptic pedicles.

Cellular proliferation. In some fish, the thymidine analog 5-bromo$2^{\prime}$-deoxyuridine (BrdU; Sigma, St. Louis, MU) was injected intraocularly through the nasal cornea (estimated intraocular concentration 20 $\mu \mathrm{M}$; Raymond et al., 1988) to label proliferating cells. In fish with retinal excisions, a single injection of $\mathrm{BrdU}$ was made 1,2 , or 3 weeks after surgery ( $n=3,2,2$, respectively), and the fish were sacrificed 1 d later. Two other fish had BrdU injected 14 or $19 \mathrm{~d}$ after surgery, and were sacrificed 49 and $104 \mathrm{~d}$ later, respectively. In fish with single slit incisions, a single injection of BrdU was made 1,2 , or 3 weeks after surgery $(n=2,2,1$, respectively), and the fish were sacrificed $1 \mathrm{~d}$ later. All eyes injected with BrdU were processed as whole-mounts (see above) without Dil application to the optic nerve. The whole-mounts were washed three times with phosphate buffered saline, $0.3 \%$ Triton-X (PBS/Tx), and then treated with PBS/Tx/2N HCl for $1 \mathrm{hr}$, followed by PBS/Tx washes.

In whole-mounts BrdU was visualized with fluorescence immunocytochemistry. The tissue was incubated with $10 \%$ normal goat serum in PBS/Tx for $1 \mathrm{hr}$, transferred to 10\% anti-BrdU mouse monoclonal antibody (Amersham, Arlington Heights, IL) in PBS/Tx/0.5\% bovine serum albumin for $24-48 \mathrm{hr}$ at $5^{\circ} \mathrm{C}$, and then incubated in $1 \%$ goat antimouse antibody (TRITC conjugated) in PBS for $24 \mathrm{hr}$ at $5^{\circ} \mathrm{C}$. The reacted whole-mounts were washed in PBS, coverslipped on a glass slide with $50 \%$ glycerol in phosphate buffer, and visualized with rhodamine-cube epiffuorescence microscopy.

Some retinas were examined as frozen sections. Eye cups were bisected along a line connecting the dorsal-most point of the optic papilla to the center of the lesion, and at the corresponding location in the unoperated retina, infiltrated with $5 \%$ sucrose, $0.1 \mathrm{M} \mathrm{PO}_{4}$ buffer for 1 hr, and $15 \%$ sucrose, $0.1 \mathrm{M} \mathrm{PO}_{4}$ buffer overnight. The next day the tissue was infiltrated with $7.5 \%$ gelatin, $15 \%$ sucrose, $0.1 \mathrm{M} \mathrm{PO}_{4}$ buffer twice for $2 \mathrm{hr}$ at $37^{\circ} \mathrm{C}$, and the eye cup pieces were embedded in the same solution at room temperature, and frozen by immersion in isopentane chilled with dry ice. Cryosections ( $20 \mu \mathrm{m}$ thickness) were made at $-30^{\circ} \mathrm{C}$, with the plane of section radial to the retina and parallel to the horizontal meridian. Sections were melt-mounted onto gelatin subbed glass slides, incubated with the primary anti-BrdU antibody (1: 50 dilution) and a secondary antibody conjugated with peroxidase (1: 200 dilution). BrdU-positive nuclei were visualized with the diaminobenzidine/ $/ \mathrm{H}_{2} \mathrm{O}_{2}$ reaction.

Some whole-mounts and frozen sections were incubated with phalloidin (which labels actin). The whole-mounts and slides were incubated with $2.5 \mu \mathrm{g}$ of FITC-conjugated phalloidin (Sigma) per $\mathrm{ml}$ of $0.1 \mathrm{M}$ $\mathrm{PO}_{4}$ buffer at room temperature for $12 \mathrm{hr}$. The tissue was then washed with buffer and examined with epifluorescence microscopy.

\section{Results}

This section is divided into four parts. In the first, we describe the cellular proliferation associated with surgical lesions to the retina; this information will be useful in the analysis of the origins of new retinal cells in the third and fourth parts. The second part describes the mechanical distortions of the retina caused by the surgery, especially as they pertain to the suspected nonproliferative spread into the lesion. The third part describes the origin and disposition of new cones in the stretched retina adjacent to the lesion; this is the longest section and contains the most surprising results. The fourth part describes the regeneration of retina inside the ablated region, as distinct from the surrounding region that was stretched but otherwise intact. In the final two parts, only the photoreceptor layer is analyzed, particularly the cones.

\section{Cellular proliferation in central retina: effects of surgery}

In the adult fish retina, the only cells that are normally proliferative are the rod precursors and Müller glia in central retina and the neuroepithelial cells in marginal retina (for review, see Powers and Raymond, 1990). Lombardo (1972) first showed that proliferation in the marginal cells increased following surgical insult, and Hitchcock et al. (1992) confirmed that result. Here we restrict our attention to proliferating cells in central retina. BrdU was injected into eyes 1,2 , or 3 weeks following surgery, and the retinas' were removed $1 \mathrm{~d}$ after injection.

In those fish injected 1 week after surgery (patch removal or simple slit incision), there were four distinct classes of labeled cells. Heavily labeled cells lined the lesion (region L in Fig. 2). These cells constituted the wound blastema, the cells that will form the regenerated retina (Hitchcock et al., 1992); these cells were, of course, not present in unoperated retina. A second group of cells was the most superficial (near the inner limiting membrane), and was distributed as a wedge-shaped cluster, reminiscent of a trail of ants, extending from the optic papilla toward the lesion site (arrowheads, Fig. 2). This region is occupied by degenerating RGC axons that were severed by the surgery, and the labeled cells might be involved in phagocytizing the axonal debris. Such cells were not observed in unoperated retina, and it is not known if they originated in the retina or migrated there from elsewhere. The third group lay in the inner nuclear layer (INL; Fig. $3 a, b$ ). In unoperated retinas labeled cells were only rarely observed at that level, as isolated units or in small clusters; they were presumed to include both rod precursors and Müller glia (Raymond and Rivlin, 1987). In operated retina the number and sizes of the clusters were increased (Fig. 3a). The elevated numbers could reflect either more of the same two cell types or the addition of another cell type normally quiescent or absent. The fourth group was widely dispersed in the outer nuclear layer (ONL), generally as isolated cells or small clusters (Fig. $4 b$ ). These cells were labeled in both operated and unoperated retinas, but they were more numerous in the operated retinas, where their densities were greatest adjacent to the lesion (approximately $160 \%$ greater than unoperated retina) and decreased roughly linearly with distance away from the lesion (Fig. $4 c$ ). In normal retinas, labeled cells in the ONL are exclusively the rod precursors (Raymond and Rivlin, 1987). In the operated retinas the labeled cells in this location must include the rod precursors, and the elevated numbers could imply either that the rod precursors had become more proliferative or more numerous, or that they had been augmented by another class of pro- 


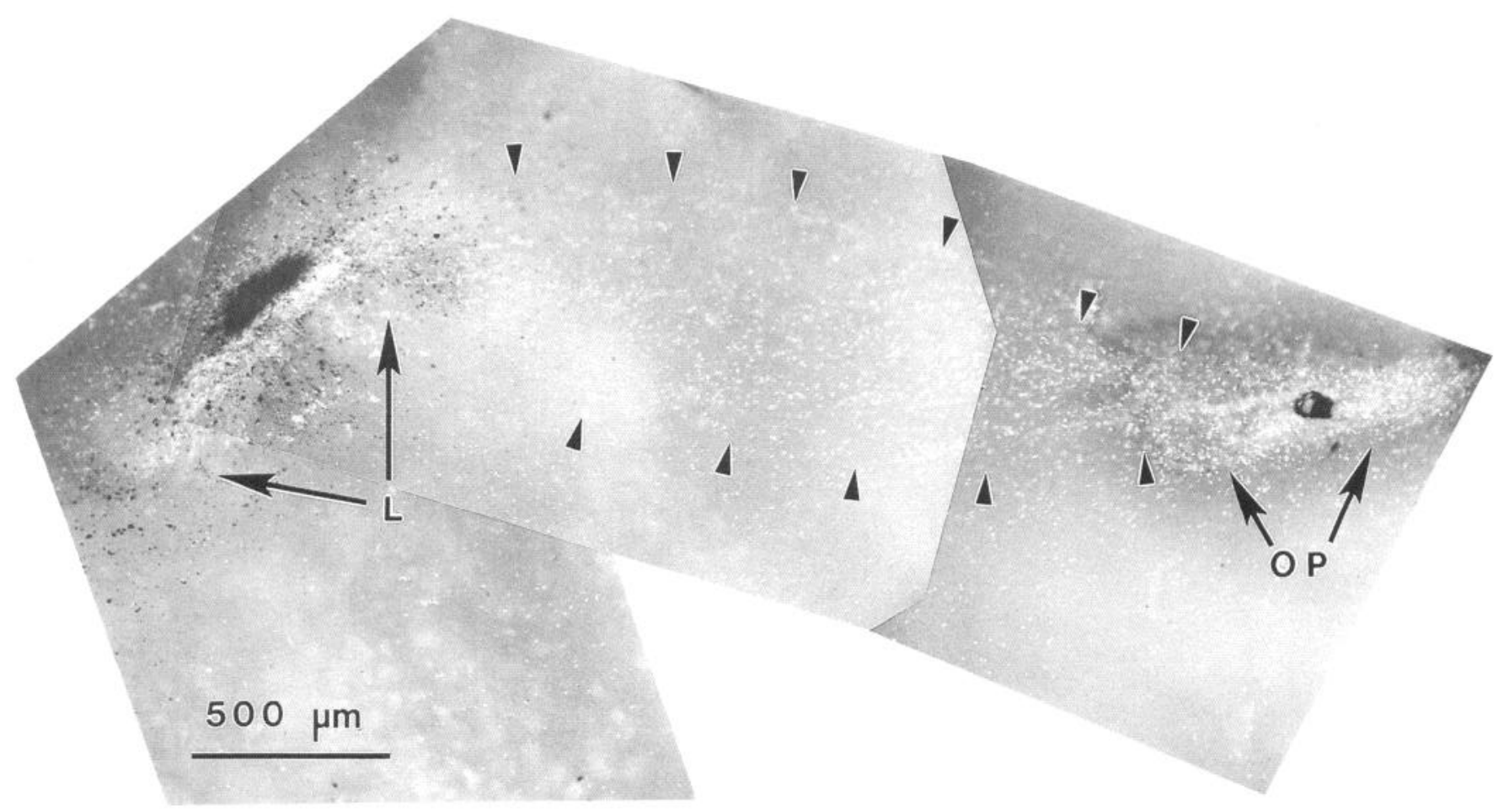

Figure 2. Whole-mounted retina, $8 \mathrm{~d}$ after surgery, and $1 \mathrm{~d}$ after BrdU injection. Between the optic papilla $(O P)$ and the site of a single slit lesion $(L)$, an "ant trail" of white BrdU-positive nuclei is present (arrowheads).

liferative cell, perhaps a cell type that is normally quiescent. These alternatives can not, at present, be distinguished experimentally because there is no available cellular marker that can distinguish between rod precursors and other proliferative cell types.

In the retinas injected with BrdU 2 weeks after surgery, the same four groups were evident, but some of their numbers had changed. The presumably phagocytic cells that formed the "ant trail" were less numerous, and the number and sizes of the clusters in the INL were diminished (Fig. 3b). The wound blastema and the proliferative cells in the ONL appeared unchanged from 1 week.

The retinas injected with BrdU three weeks after surgery were examined only in radial sections, which did not permit any conclusion about the state of the superficial "ant trail." The wound blastema was still prominent in those retinas from which a patch had been removed, consistent with an earlier report (Hitchcock et al., 1992). In both patch removal and slit incision lesions, the numbers of labeled cells in INL and ONL were not significantly different from unoperated retina.

In summary, the proliferative activity in the region surrounding the lesion was markedly elevated by 1 week after both types of surgery, less so at 2 weeks, and had returned to nearly normal levels by 3 weeks.

\section{Mechanical distortions of the retina associated with surgery}

Removal of a small patch of retina resulted in a mechanical distortion of the surrounding retina that was evident within $2 \mathrm{~d}$. In the open eye-cup, before it was flattened for whole-mounting, the retinal sector that included the lesion was thrown into folds with their long axes perpendicular to the nearest wound bound- ary. Folding was pronounced on the central side and much less noticeable on the peripheral side. No folds were noted lateral to the lesion. The fact that the central folds were evident in the intact eye cup, before fixation and flattening, ruled out any trivial explanation associated with the dissection. The existence of the folds indicated that the retina bounding the central edge of the lesion was now too broad to fit into its current space. Prior to the lesion, the retina was unfolded, therefore either the retina expanded or the available space contracted. Retinal expansion could not be evaluated directly, but the alternative, that the length of the central edge of the wound contracted as the lateral edges of the wound drew together, had clear implications that could be evaluated. If the lateral edges had moved together, the retina bounding the lateral wound edges would be stretched. This prediction is strongly supported by the observations given below.

Retinal stretch was revealed by changes in three independent morphological features: the course of DiI-labeled RGC axons, the distribution of the annuli of DiI-labeled RGC somata, and the highly ordered pattern of double cones (DCs). In normal temporal retina, RGC axons converge directly from their somata toward the optic papilla, the labeled annuli are contiguous and circular, and the DCs are arranged in "spokes" that extend in the centroperipheral direction parallel to the RGC axons (Cameron and Easter, 1993). In the retinas with a patch removed, the axons and the spokes were locally deflected toward the center of the lesion. The spokes and axons immediately adjacent to the lesion bent the most, but as much as $500 \mu \mathrm{m}$ lateral to the lesion a bend could still be discerned (Fig. $5 a, b$ ), implying that the retina had been tugged toward the lesion. The effects of this "tug" extended even further, as evidenced by an increase in the 

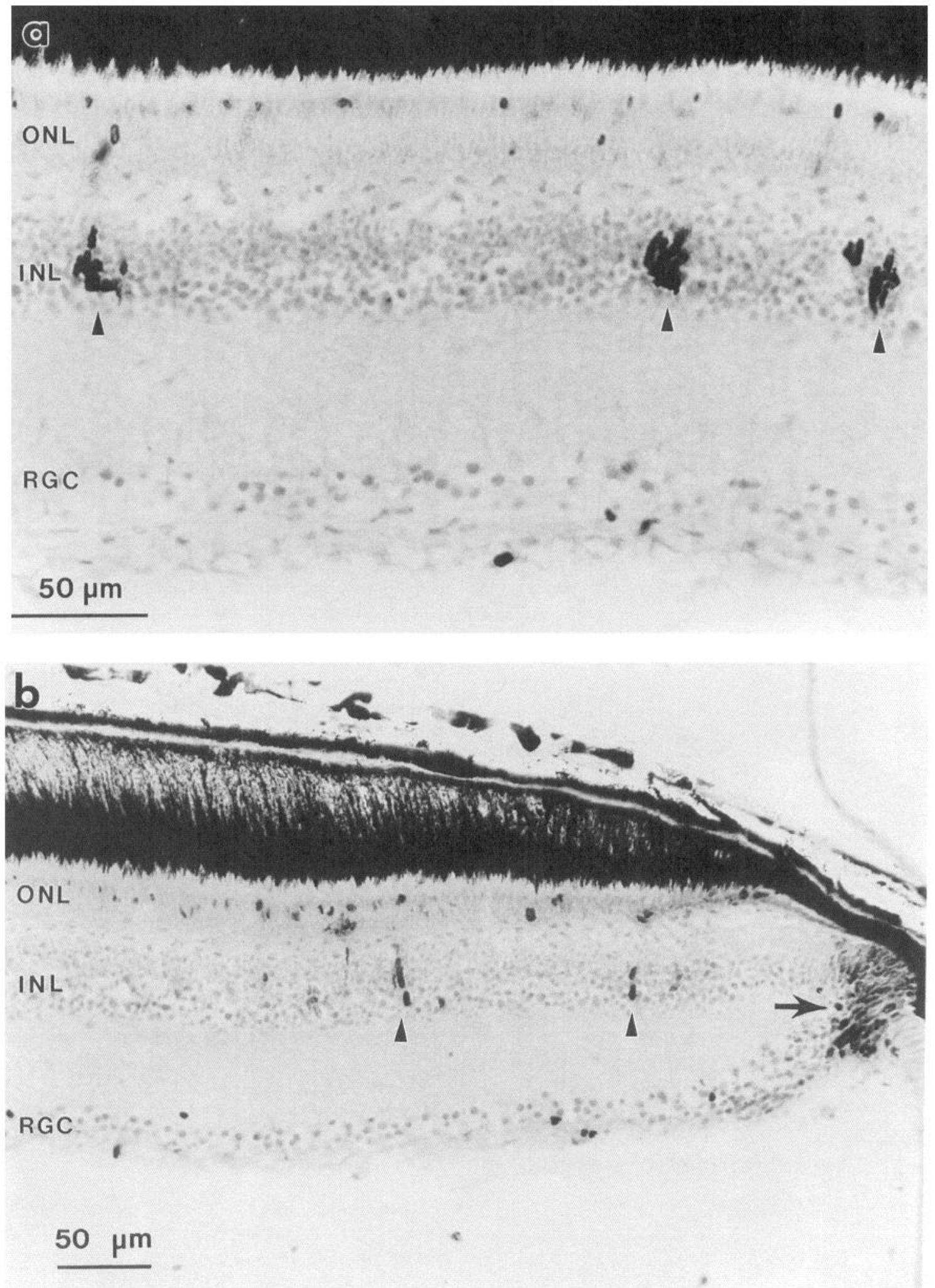

Figure 3. Radial sections of retinas labeled with BrdU 1 and 2 weeks following surgery. $a, 8 \mathrm{~d}$ following surgery, clusters of BrdU-positive nuclei (dark cells, arrowheads) are present in the INL; such clusters are never seen in unoperated retinas. Single labeled cells are seen in the ONL. Displayed region is approximately $1 \mathrm{~mm}$ from the lesion site. $b, 15 \mathrm{~d}$ following surgery, clusters of BrdU-positive nuclei in the INL are present (arrowheads), but diminished relative to one week earlier. Labeled cells in the ONL are similar to 1 week earlier. Displayed region is between the lesion site (out of view to the left) and the retinal margin, to the right. The proliferative marginal germinal zone is indicated (arrow). $R G C$, Retinal ganglion cell layer. 

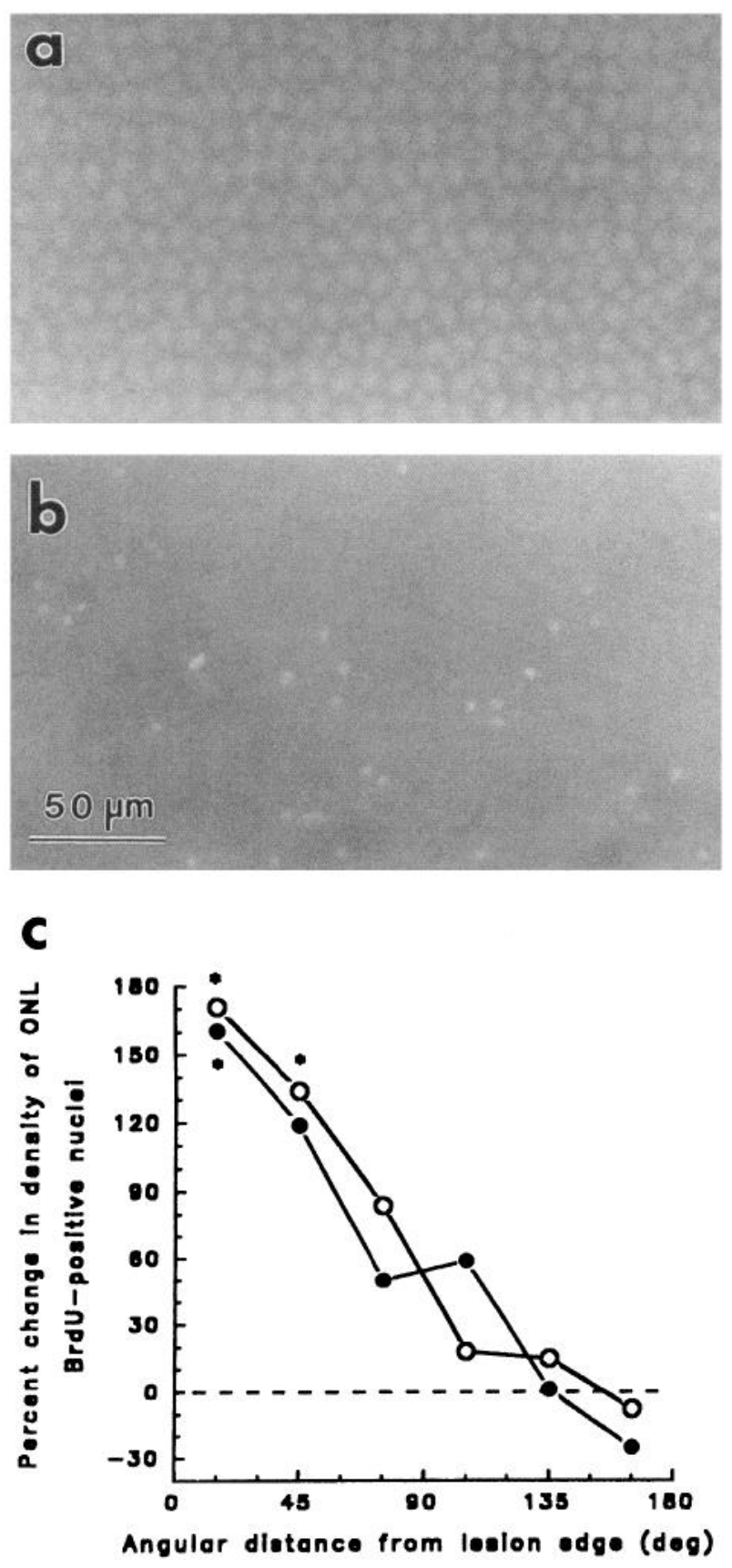

Figure 4. BrdU-positive nuclei in retina lateral to the lesion. BrdU was injected intraocularly one week after surgery, the fish sacrificed the next day, and a retinal whole-mount was prepared for anti-BrdU immunocytochemistry. $a$, Cone photoreceptor mosaic viewed with epifluorescence microscopy, focal plane in the ellipsoids. The large white structures are the double cones, the smaller ones are single cones. $b$, Same field as in $a$, but the focal plane is approximately $10 \mu \mathrm{m}$ less deep, at the level of the ONL, where white BrdU-positive nuclei are visible. $c$, The percent change in the density of BrdU-positive nuclei $\{$ ([øperated - unoperated]/unoperated $) * 100\}$ as a function of angular distance from the lesion edge. Solid symbols, Patch removed; open symbols, single slit incision. Asterisks indicate statistically significant differences in the operated and unoperated densities $(P<0.05$, independent Student's $t$ test). distance between spokes $60^{\circ}$ (roughly $2 \mathrm{~mm}$ ) from the edge of the lesion (Fig. 1e; compare arrowheads in Fig. $6 a, b$ ). The mean interspoke distance in the $30^{\circ}$ sector adjacent to the lesion edge increased from $11.1 \pm 0.9 \mu \mathrm{m}$ to $14.1 \pm 1.5 \mu \mathrm{m}$, and over the next $30^{\circ}$ sector, from $12.4 \pm 0.6 \mu \mathrm{m}$ to $14.8 \pm 1.4 \mu \mathrm{m}$ (increases of $27 \%$ and $19 \%$, respectively, $n=13$ fish). As with the increase in proliferation (Fig. $4 c$ ), the increased interspoke distance was greatest adjacent to the wound edge, and decreased roughly linearly with distance away (Fig. 6e). The increased spacing between spokes could not have resulted from the loss of spokes, because the arrangement of the DCs in adjacent spokes was unchanged from normal: concave pairs of DCs faced one another, the relation to single cones (SCs) was unchanged, and the increased spacing was distributed continuously across all spokes (Fig. $6 a, b$ ). These results confirm that the retina lateral to the lesion had been stretched to cover a larger area than it had before the surgery. The only available space for this incremental area was within the lesion; thus, the stretched retina partially filled the ablation. A similar measurement in the retina immediately adjacent to the peripheral edge of the lesion indicated that it, too, had been stretched. The number of DCs along approximately $100 \mu \mathrm{m}$ of spoke was counted, and the distance between DCs was estimated to have increased in operated retina, from $9.2 \pm 0.4 \mu \mathrm{m}$ to $11.2 \pm 1.4 \mu \mathrm{m}$ ( $22 \%$ increase, $n=5$ fish). In addition, the short, centrally directed annular hooks of DiI-labeled cells (top arrow, Fig. 1e) contain RGC somata that had previously been more peripheral, but had been drawn centrally, toward the lesion, further evidence of peripheral spread. The retinal folds central to the lesion prevented good visualization there, so the issue of filling-in from the central direction remains unresolved. In summary, the area of the ablation was initially reduced by a nonproliferative filling-in from the lateral and peripheral sides, and possibly from the central side as well.

The data in Figure $6 e$ permitted an estimation of the amount of filling-in by the retina lateral to the lesion. The mean increase in interspoke distance over the $60^{\circ}$ sector lateral to the lesion was $23 \%$. The length of the $60^{\circ}$ arc at the lesion eccentricity was roughly $2 \mathrm{~mm}$ in most fish, and this length multiplied by 0.23 gives $460 \mu \mathrm{m}$. This amount of spread from both lateral edges sums to create a total lateral fill-in of nearly $1 \mathrm{~mm}$. The amount of filling-in from the centroperipheral direction must be at least equal to the central component of the annular hook, which in Figure $1 e$ is about $200 \mu \mathrm{m}$.

In retinas with a slit incision, none of the three indicators (RGC axons, RGC somata annuli, DC spokes) were distorted, nor did the interspoke distances change (Fig. 7a). Surgical trauma alone, which was sufficient to evoke substantial changes in proliferative activity (open symbols, Fig. 4c), did not evoke stretch. A hole in the retina was thus required to induce retinal stretch.

The possibility that the retinal stretch was an artifact of fixation or whole-mounting was evaluated in two ways. First, the area of the ablation was measured in one retina immediately after surgery but before fixation, and then again after $24 \mathrm{hr}$ of fixation. Before fixation, the wound area was $2.2 \mathrm{~mm}^{2}$, and after fixation $2.3 \mathrm{~mm}^{2}$ (a $5 \%$ increase, but probably not significant). The small increase is consistent with a withdrawal of the tissue away from the wound, rather than a movement into it, and might be attributed to fixation-associated shrinkage of the tissue. Second, we noted that long after the entire wound was filled (see below), the interspoke distances lateral to the lesion site remained elevated (Fig. $6 f$ ). These results indicate that the ob- 

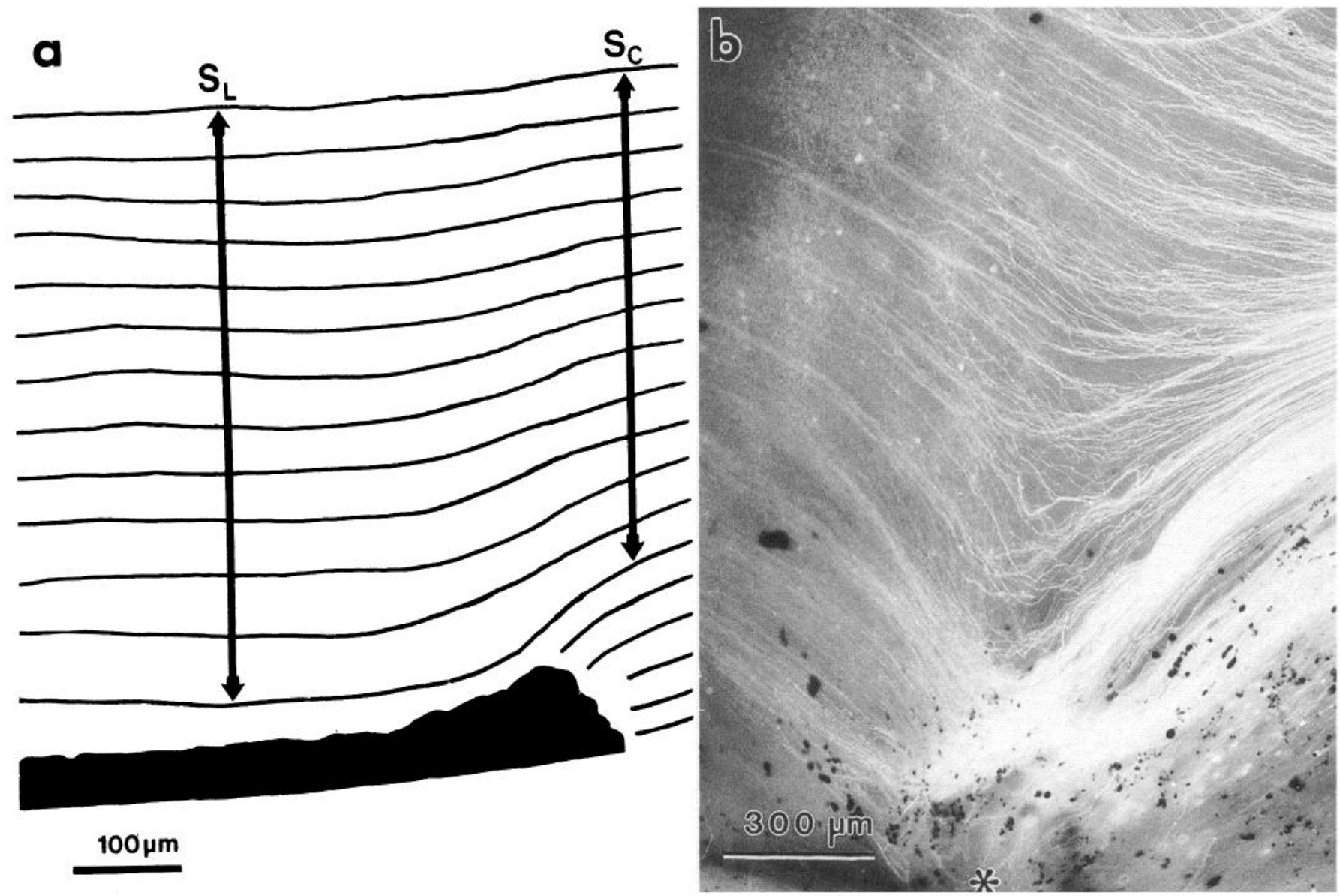

Figure 5. Evidence for retinal stretch lateral to lesion sites. Retinal margin is towards the left in both views. $a$, Line drawing of representative spokes of DCs lateral to a dorsal lesion edge (black area at the bottom), $2 \mathrm{~d}$ following surgery. Such spokes typically extend linearly from the retinal periphery toward the optic papilla, but here they are deflected toward the wound. The distance $S_{L}$ exceeds $S_{c}$, although both lines link the same spokes. $b$, Bending of DiI-labeled axons towards a lesion site (asterisk) $45 \mathrm{~d}$ after surgery. Such axons typically extend straight from their somata to the optic papilla (compare to the nasal hemiretina of Fig. 1e).

served retinal stretch was not an artifact of either fixation or mounting.

The possibility that actin provided the force that drew the lesion edges toward the center of the wound, as occurs in chick epidermis wound healing (Martin and Lewis, 1992) was evaluated. We incubated lesioned retinas with fluorescent phalloidin, a specific marker for actin, but did not observe any concentrated, belt-like labeling in either the neural or pigmented retinas near the lesion. We thus conclude that either the purse strings responsible for the wound closure are made of some material other than actin, or that the purse string analogy is invalid. If there are no intraretinal "purse strings," then the edges were probably drawn together by contractile elements inside the ablated region.

In summary, the wound boundaries spread inward, partially covering the lesion and stretching the surrounding retina.

\section{New cones in stretched retina}

Cone mosaics in operated eyes were observed in whole-mounts $2-430 \mathrm{~d}$ after surgery. The boundary between regenerated retina (the former lesion site) and the surrounding, stretched retina was evident from two features. First, annuli of DiI-labeled ganglion cells were interrupted at both lateral edges of a lesion (Fig. 1e). Second, the cone mosaics of regenerated and stretched retina were different. The regenerated retina was completely disor- dered (see below). Stretched retina maintained the normal orderly pattern of SCs and DCs at least until $10 \mathrm{~d}$ after surgery, and this pattern was still evident thereafter, but it was degraded by the presence of new elements that appeared to be cones (compare Fig. $6 c, d$ ).

Because the identities of the new elements could not be determined from the whole-mounts, the cone mosaics were examined electron microscopically. In all retinas, both operated and unoperated, SCs and rods were readily distinguished by their different cross-sectional areas (rods, $3.2 \pm 0.5 \mu \mathrm{m}^{2}, n=80$; SCs, $24.9 \pm 5.4 \mu \mathrm{m}^{2}, n=300$ ). Because all of the retinas were fully light adapted, rods also differed from cones because rods occupied a more scleral radial position, due to photomechanical retinomotor movements (Burnside and Nagle, 1983; Dearry and Barlow, 1987). SC and DC ellipsoids differed in cross-sectional area (DCs, $37.0 \pm 7.4, n=325$ ) and shape, SCs being circular and DCs being roughly elliptical (Fig. 8a). Additional morphological features distinguished SCs from DCs. Electron-dense mitochondria were clustered near the center of SC ellipsoids, whereas electron-dense mitochondria were clustered along the common border of the DCs' paired cones (Rowe et al., 1994; Fig. $8 a, b)$. Each paired cone of a DC had an electron-dense, intracellular, subjunctional cisterna along the common apposition (Fig. 9a). Such cisternae, which have been described pre- 

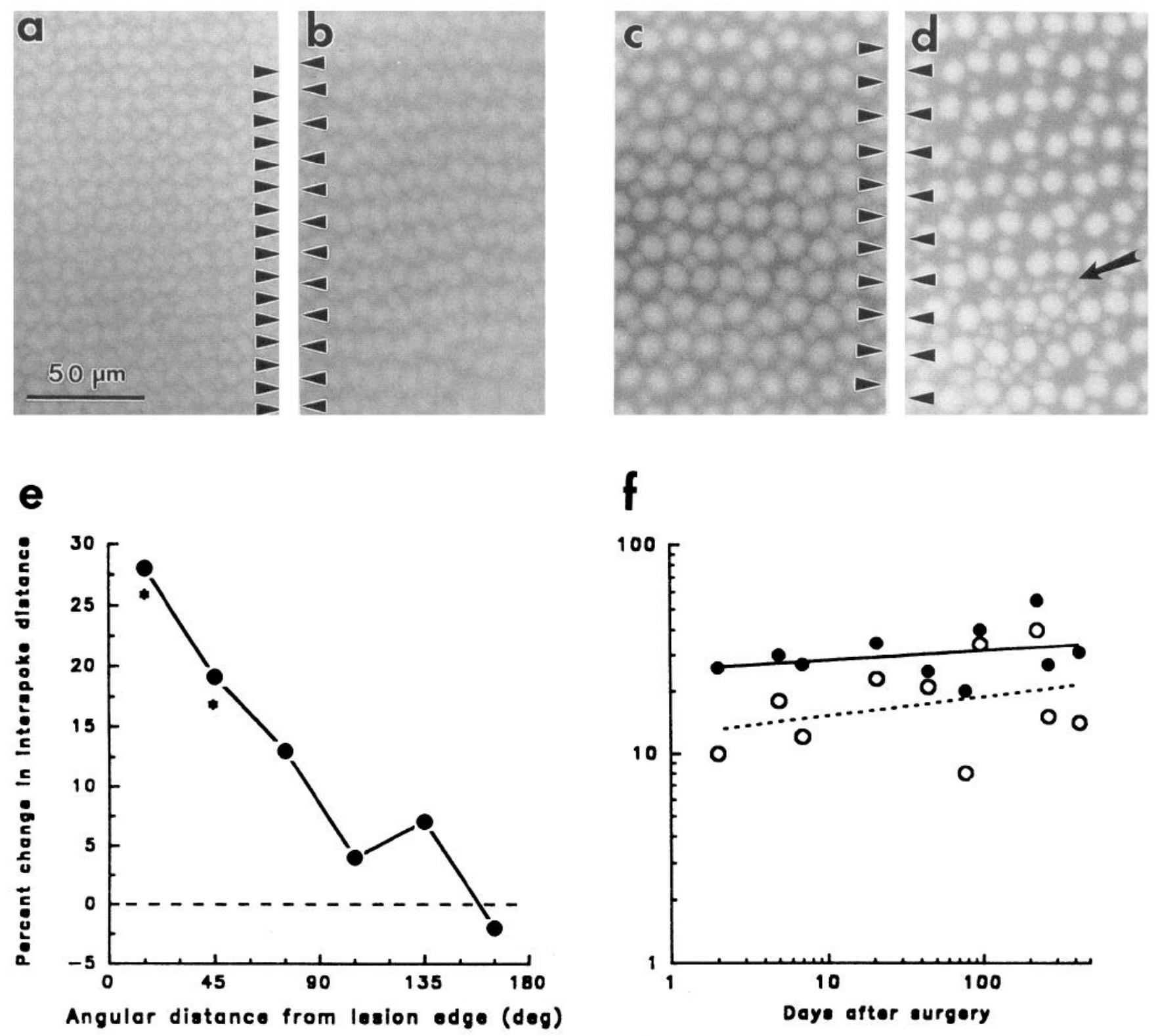

Figure 6. Cone mosaics viewed in retinal whole-mounts from unoperated $(a, c)$ and operated retinas $(b, d), 2 \mathrm{~d}(a, b)$ and $45 \mathrm{~d}(c, d)$ after surgery. The centroperipheral direction is horizontal, parallel to the spokes of double cones (arrowheads). In $a$ and $b$, the distance between the spokes of double cones is increased in operated retina within $30^{\circ}$ of the lesion site, evidence for stretch. Forty-five days after surgery, the distance between the spokes is still elevated in operated retina, but the stretched mosaic $(d)$ is augmented by many extra cones, several of which are indicated by the arrow. $e$, Percent change in interspoke distance as a function of angular distance from the lesion. Asterisks indicate statistical significance $\left(P<0.05\right.$, independent Student's $t$ test). $f$, Percent change in interspoke distance within $0-30^{\circ}$ (solid symbols) and $31-60^{\circ}$ (open symbols) of a lesion edge (i.e., the regions of statistical significance in $e$ ) as a function of time after surgery. Interspoke distance did not change with time after surgery (linear regressions: solid line, $R^{2}=0.09$; dotted line, $R^{2}=0.11$ ). Data points for 2,7 , and $21 \mathrm{~d}$ after surgery represent means of two fish.

viously in the paired cones of other teleost species (Berger, 1967; Borwein and Hollenberg, 1973; Cantino et al., 1986) were never observed in rods or SCs.

The fundamental rhombic pattern in stretched retina was evident in the electron micrographs (dotted lines, Fig. $8 b$ ), but it was modified by the addition of extra cones. Anomalous SCs were at sites normally free of cones (ASC, Fig. 8b); anomalous DCs were at sites normally occupied by SCs (ADC, Fig. $8 b$ ) or at sites normally free of cones; triple cones (TCs), a cone morphology never seen in unoperated retina, were at some DC sites (TC, Fig. 8b); and another atypical morphology, the quadruple- cone (QC; see Fig. 13a), was also occasionally observed. All DCs in stretched retina resembled those in unoperated retina, regardless of their position in the mosaic. For example, the paired members of anomalous DCs had the mitochondrial distribution and subjunctional cisterna typical of normal DCs (Figs. $8 b, 9 b)$. The TC members also resembled individual DC members by having electron-dense mitochondria clustered near their common apposition (TC, Fig. $8 b$ ) and subjunctional cisternae (Fig. 9c).

The cone morphologies were examined further to determine if the extra cones might be functional. TC outer segments in 


\section{a}

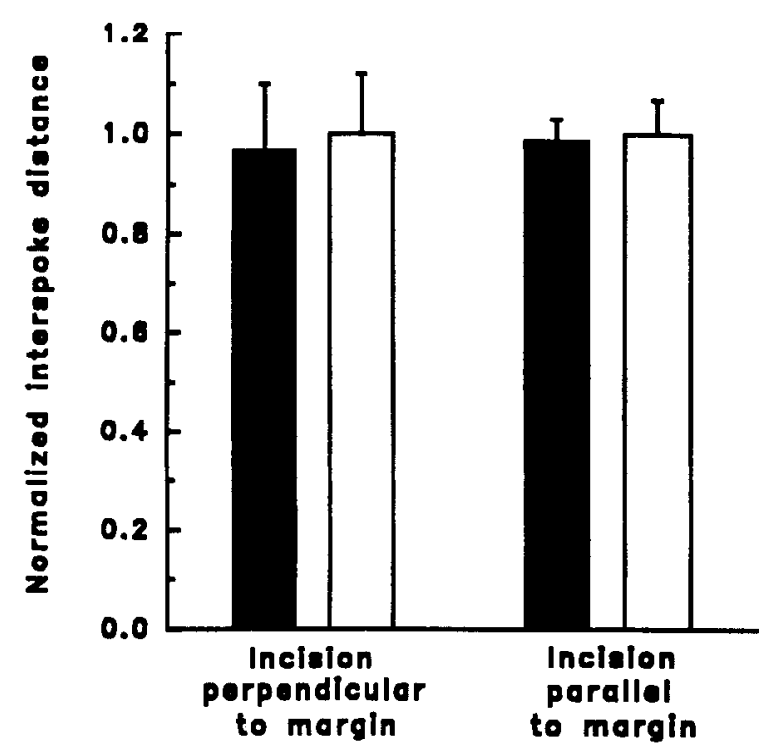

b

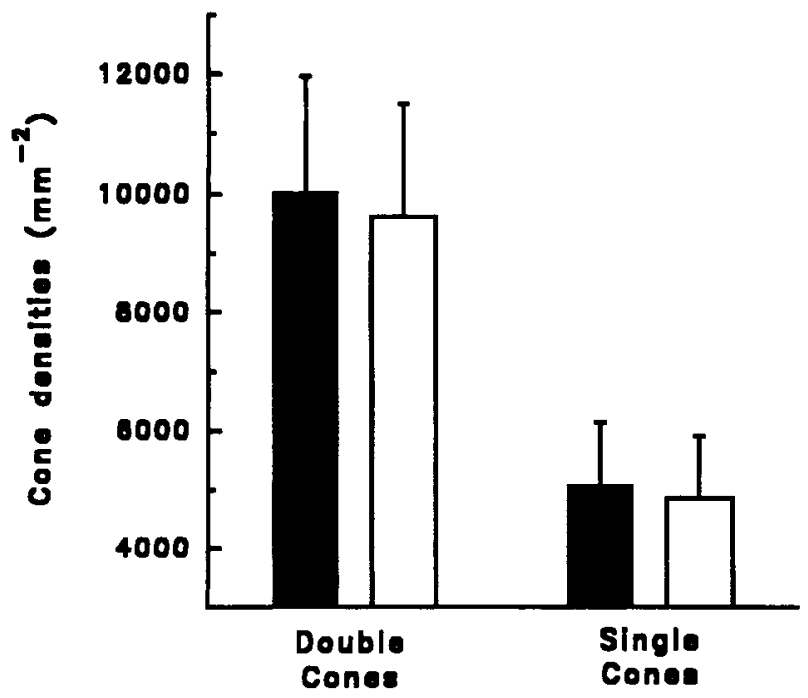

Figure 7. Single-slit incisions do not cause retinal stretch or anomalous cone production. $a$, Normalized mean interspoke distances $( \pm 1$ SD) within $30^{\circ}$ of the incision site, in two groups that received single slit incisions parallel or perpendicular to the retinal margin, $45 \mathrm{~d}$ after surgery ( $n=2$ fish in each group). There was no statistically significant difference between unoperated (open bars) and operated (solid bars) rctinas, indicating that the retina had not been stretched. $b$, Cone densities from the "perpendicular" group in $a$. There was no significant difference in the densities of double cones or single cones between operated (solid bars) and unoperaled (open bars) retinas, indicating that no extra cones were added into the mosaic of single slit incised retinas (means $\pm 1 \mathrm{SD}$ ).

stretched retina were observed, and one TC and an anomalous DC were followed through serial sections from the level of ellipsoids to that of the synaptic pedicles. Each cone member had a pedicle in the same layer as the others (Fig. 10c), in spatial register with its overlying ellipsoid and nucleus (Fig. 10a,b). Moreover, each pedicle had multiple synaptic ribbons, multiple invaginating processes, and a large number of synaptic vesicles (Fig. 10c). These results indicated that at least some of the extra cones in stretched retina had anatomical features associated with functional photoreceptors.

The relative numbers of the four morphological classes of cones differed in unoperated and stretched retina. The normal ratios,

$$
\text { [SC:DC:TC:QC], }
$$

were $[0.50: 1.00: 0.00: 0.00]$. In stretched retina, the ratios

$$
[(\mathrm{SC}+\mathrm{ASC}):(\mathrm{DC}+\mathrm{ADC}): \mathrm{TC}: \mathrm{QC}]
$$

were [1.01:1.00:0.14:0.01], indicating a relative excess of the SC phenotype (SC+ASC) and novel compound cones (TC and QC). The planimetric density of individual cone cells in stretched retina,

$$
\begin{aligned}
\{[(\mathrm{SC}+\mathrm{ASC}) * 1] & +[(\mathrm{DC}+\mathrm{ADC}) * 2] \\
+ & {[\mathrm{TC} * 3]+[\mathrm{QC} * 4]\} / \mathrm{mm}^{2} }
\end{aligned}
$$

(determined from electron micrographs within $30^{\circ}$ of a lesion site), was roughly $20 \%$ greater than normal, with $80 \%$ of this increase due to the ASCs. However, the planimetric density of all cone types,

$$
[\mathrm{SC}+\mathrm{DC}+\mathrm{TC}+\mathrm{QC}] / \mathrm{mm}^{2},
$$

within $30^{\circ}$ of a lesion site (measured from retinal whole-mounts as in Fig. 6d, 45-430 d after surgery) was not significantly different from normal $(0.99 \pm 0.06$ of unoperated retina).

The orientations of the axes of the subjunctional cisternae in DCs differed in normal and stretched retina. The DC orientations in normal retina formed two discrete populations (Fig. 11a), consistent with rhombic units, as described earlier (Cameron and Easter, 1993). In stretched retina, the DC and ADC orientations also formed two populations, consistent with a degraded set of rhombic units: the distributions were broader, with nearly all possible orientations represented (Fig. $11 b$ ).

The maintenance of rhombic units in the stretched cone mosaic outside the lesion (Fig. $8 b$ ) suggested a straightforward interpretation of these results: (1) the ASCs were new cones inserted at sites where no cones had previously existed; (2) the ADCs were either a pair of new cones (if at a site where no cone had previously existed) or hybrids, one-half a previously existing $\mathrm{SC}$, the other half a new cone; (3) the TCs were hybrids, two of the elements from a preexisting $\mathrm{DC}$, the third a new cone; (4) the QCs wcre too sparse to venture an opinion on their origins.

The new cones inserted into stretched retina could have originated from either preexisting cells of a different phenotype that transdifferentiated into cones, or precursor cells that divided mitotically. The first explanation, transdifferentiation, could not be excluded by our experiments, and it remains possible that some of the new cones arose by transdifferentiation, perhaps from pigmented epithelial cells, as occurs during regeneration of amphibian retina (Stone, 1950; Reh et al., 1987).

The second explanation, mitosis, was evaluated experimentally with intraocular BrdU injections. BrdU was injected into both eyes 14 or $19 \mathrm{~d}$ after surgery, the animals were allowed to survive 49 and $104 \mathrm{~d}$ (respectively), and the retinas were processed with immunocytochemistry. BrdU-positive cone nuclei were observed outside the lesion site (Fig. 12a); such labeled nuclei were not observed in unoperated retinas (Fig. 12b). This result indicated that at least some of the new cones in stretched retina were generated mitotically after the BrdU injection.

The production of new cones might have been triggered by 

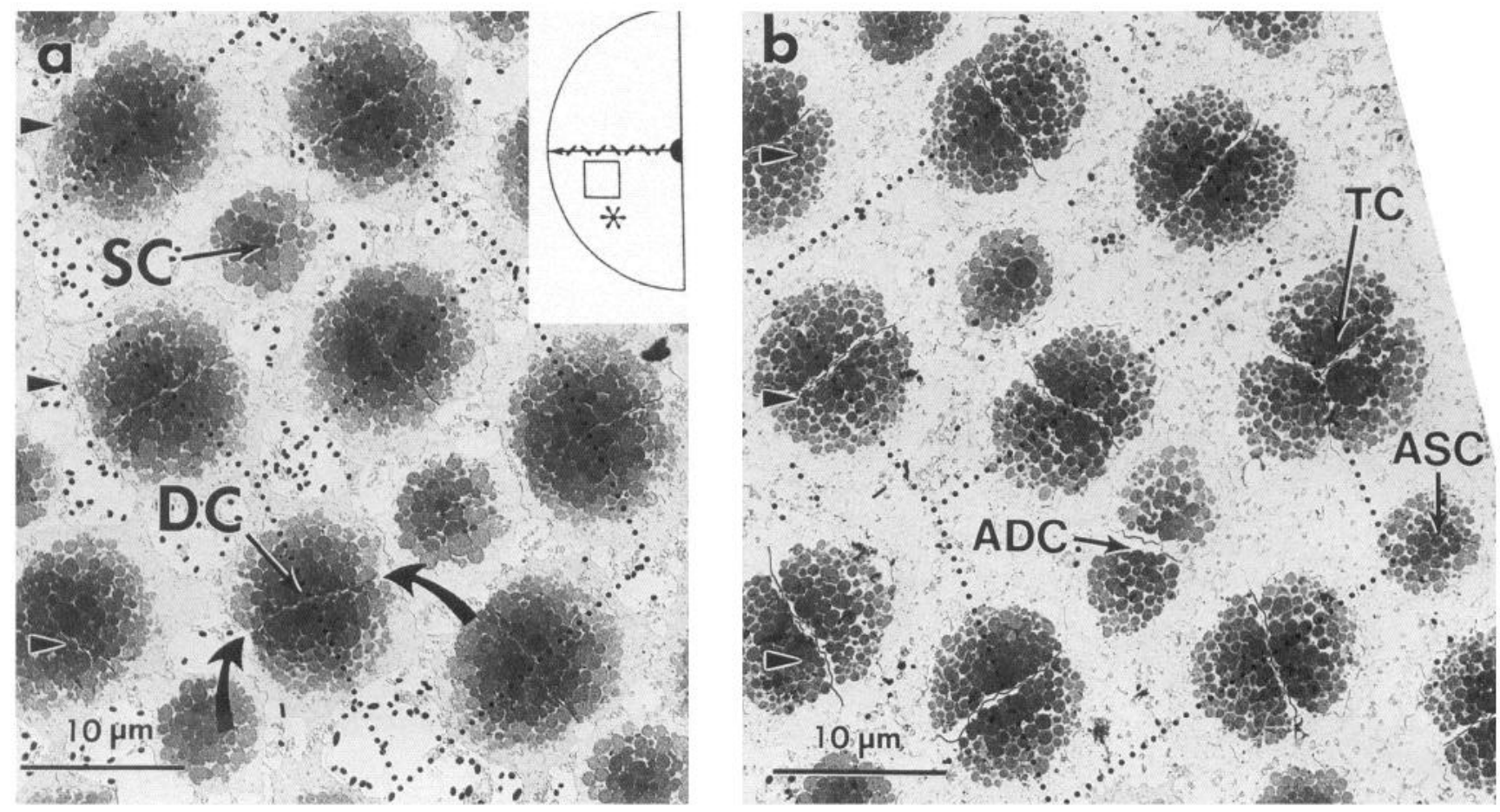

Figure 8. Electron micrographs of cone mosaics in unoperated and stretched retinas. Retinal periphery is toward the left, plane of section is parallel to the retinal surface at the level of the cone ellipsoids. $a$, Unoperated retina with double-cones $(D C)$ and single cones $(S C)$ in a rhombic pattern (dotted lines indicate two rhombic units). Arrowheads indicate spokes of DCs. Curved arrows show the junction between the two elements of the DC. Inset, Schematic of hemiretina with a lesion site (square) and a not-to-scale spoke of DCs (arrow). The approximate region of panel $b$ is indicated by the asterisk). $b$, Cone mosaic in stretched retina, $198 \mathrm{~d}$ after surgery. The mosaic has DCs and SCs in two rhombic units (dotted lines), but it is augmented by an anomalously positioned SC (ASC), an anomalously positioned DC (ADC), and a triple cone (TC).

either the surgical removal of the retinal patch or the subsequent stretch. The effects of surgical trauma alone were evaluated by cutting through the retina without removing any of it. As presented earlier (Fig. $4 c$ ), this procedure increased the number of proliferative cells, but the retina adjacent to the slit was neither stretched (Fig. 7a) nor augmented by new cones (Fig. 7b). Apparently, injury-induced hyperplasia alone was not sufficient to produce new cones, suggesting that stretch was necessary. Preliminary attempts to stretch intact retina in the absence of injury have been unsuccessful, so it remains uncertain if stretch alone is sufficient.

In summary, the stretched retina surrounding the lesion was augmented by new cones of both normal and abnormal morphologies. At least some of these new cones were produced mitotically and they were influenced, and were influenced by, the preexisting cones.

\section{Cone regeneration within the lesion site}

The cones regenerated within the lesion site were examined electron microscopically $198 \mathrm{~d}$ after surgery. The cone mosaic in regenerated retina was different from normal (compare Figs. 8a, $13 a$ ). "Correct" cone morphological phenotypes (SCs and DCs) were present, but so were the "incorrect" TCs and QCs. Cone outer segments (Fig. 13b) and normal-appearing cone pedicles (Fig. 13c) were present, suggesting that at least some of the regenerated cones were functional, consistent with earlier electroretinographic results (Mensinger and Powers, 1993).

The ratio of cone types (Eq. 1) was [1.06:1.00:0.26:0.02], indicating, as in stretched retina, an excess of SCs and a large number of the anomalous TCs and QCs. The distribution of DC orientations was random (Fig. $11 \mathrm{c}$ ), clearly different from the order in both unoperated and stretched retina (Fig. 11a,b, respectively). The total density of individual cone cells (Eq. 2) was roughly $80 \%$ greater than the same region of unoperated retina, with roughly $30 \%$ of the increase due to ASCs. The density of cone types (Eq. 3) was 35\% greater than unoperated retina. This elevation is similar to the $25 \%$ elevation in the density of tyrosine hydroxylase-positive cells reported for regenerated goldfish retina (Table 1 of Hitchcock and VanDeRyt, 1994).

In summary, the regenerated retina contained the same cone morphologies as stretched retina, but the spatial order was not reestablished.

\section{Discussion}

We have demonstrated that small retinal excisions are filled in by two mechanisms: an early, nonproliferative spread by the adjacent retina, and a later epimorphic proliferative regeneration of new tissue. These two mechanisms are similar to the wound responses observed in other epithelia (Bereiter-Hahn, 1986; Kumar et al., 1992; Martin and Lewis, 1992). Our results also speak to three issues that are particularly relevant to the CNS: neurogenesis, differentiation, and pattern formation, which are taken up in that order below.

\section{Neurogenesis}

Unlike rods, which are constantly being generated by rod precursors (Johns and Fernald, 1981; Johns, 1982; Raymond, 1985), cones are never normally produced in central, intact fish retina. Earlier work had shown that cones as well as most (perhaps all) 

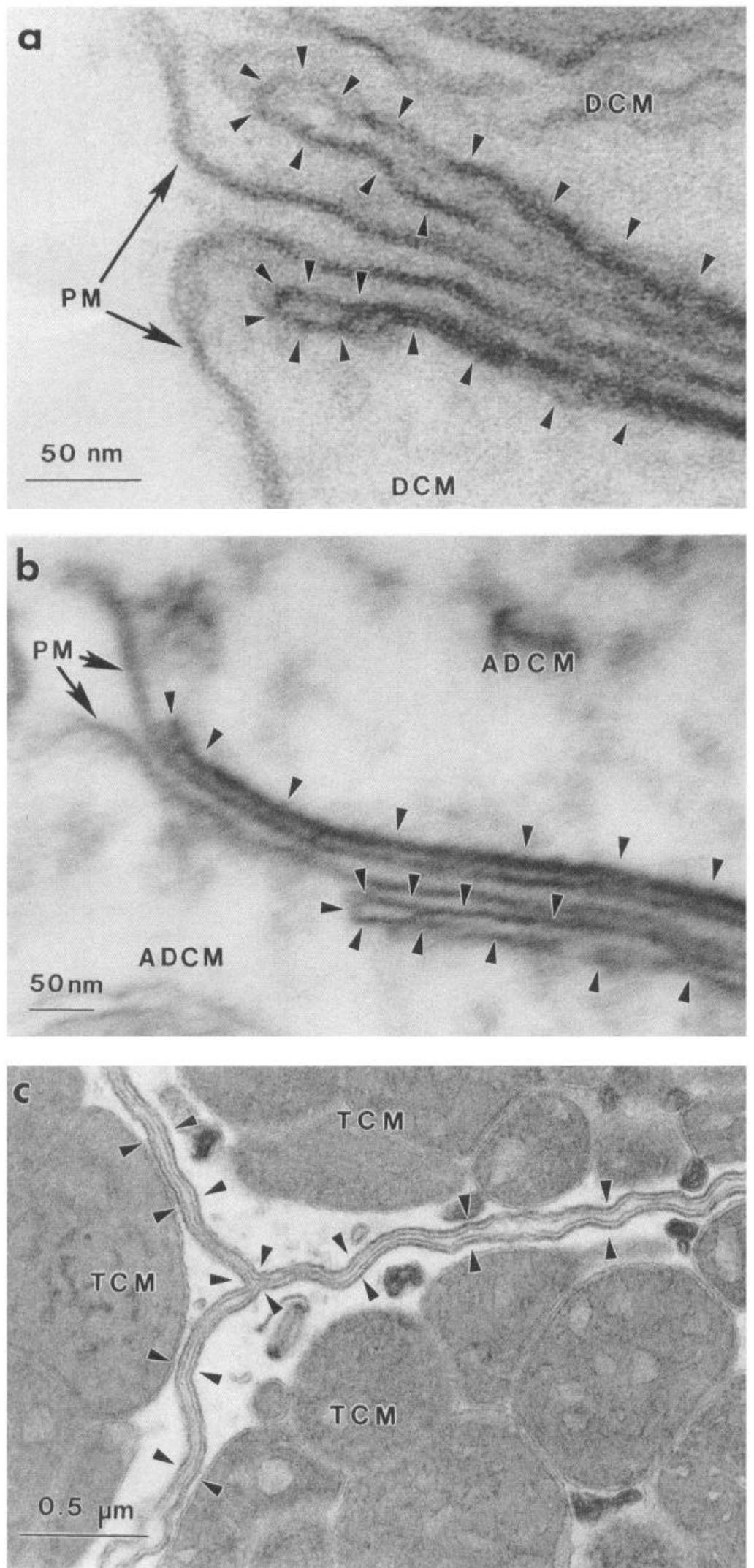

Figure 9. Electron micrographs of compound cone specializations at their ellipsoids. $a$, Each member of a normal double cone $(D C M)$ has an electron dense, subjunctional cisterna (arrowheads) that dilates slightly at the cone margin. PM, plasma membrane. $b$, Each member of an anomalous double cone $(A D C M)$ in stretched retina also has an electron dense, subjunctional cisterna (arrowheads). $c$, Each member of a triple cone (TCM) in stretched retina, like DC members, has an electron dense, subjunctional cisterna (arrowheads). retinal neurons were produced when a patch of central retina was regenerated (Hitchcock et al., 1992). We have confirmed that result, but have also demonstrated, unexpectedly, that cones were mitotically generated in stretched, but otherwise intact, ret- ina surrounding an excision. Injury alone, in the form of a single slit incision, caused neither stretch nor new cone production, although it triggered a local hyperplasia (suggesting a possible dissociation between the molecular triggers of new cone pro- 

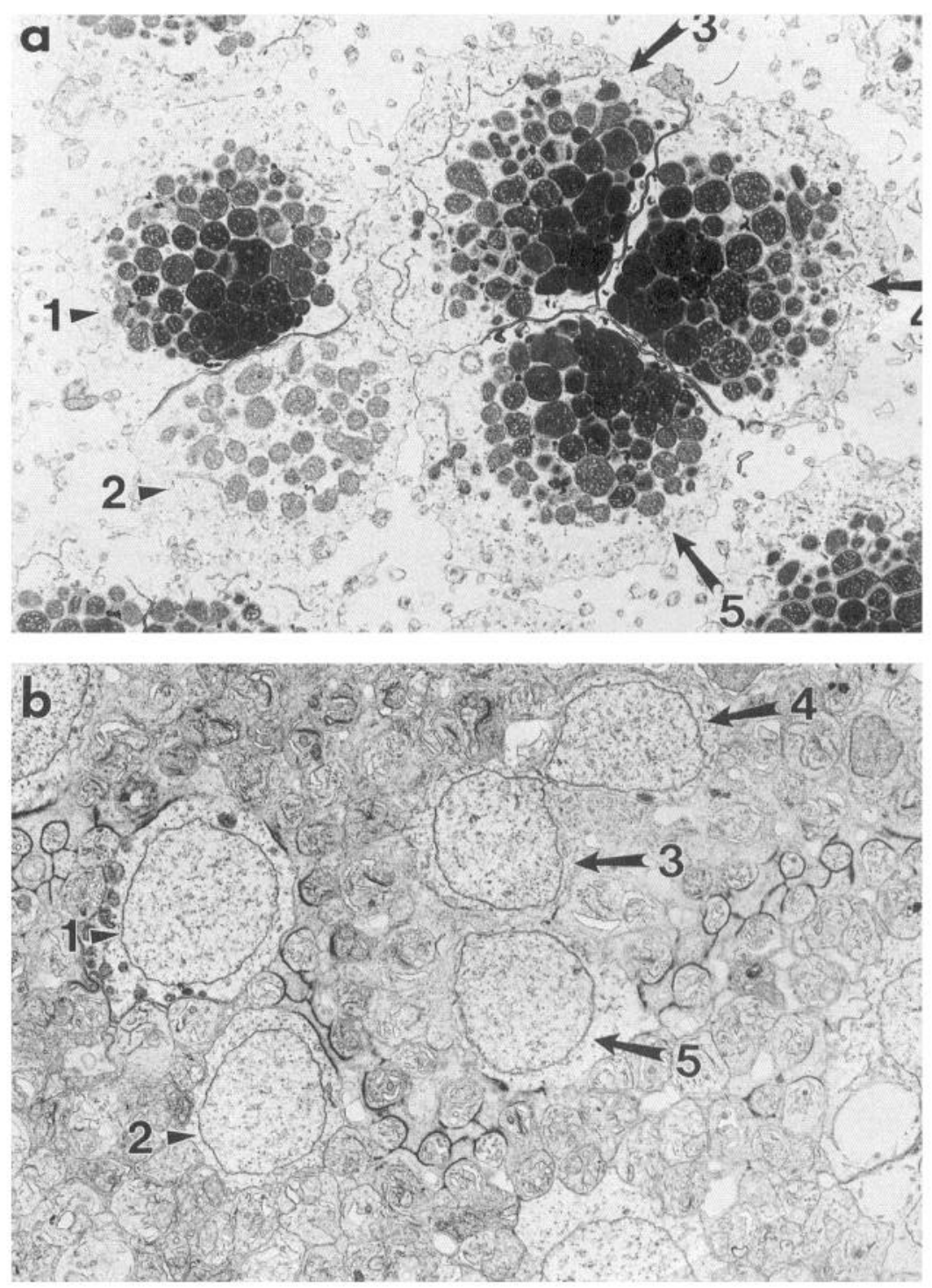

Figure 10. Evidence that new cones in stretched retina are functional. $a$, Electron micrograph of an ADC (cones 1 and 2) and a TC (cones 3-5) at the level of their ellipsoids. $b$, The same cones in $a$, approximately $7 \mu \mathrm{m}$ deeper into the retina, at the level of their nuclei. Note how cone 4 has shifted toward cone 3. $c$, The same cones in a and $b$, approximately $38 \mu \mathrm{m}$ deep to $a$, at the level of the synaptic pedicles. Note how all cones have multiple synaptic ribbons and invaginating processes. Asterisks, red spherules.

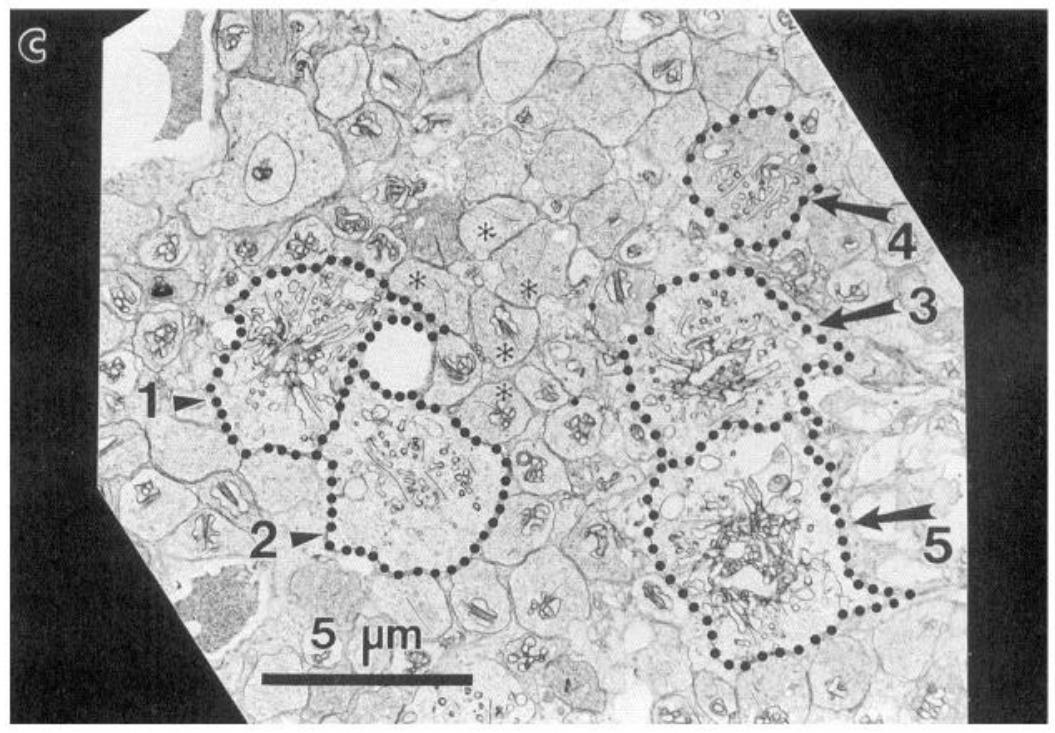




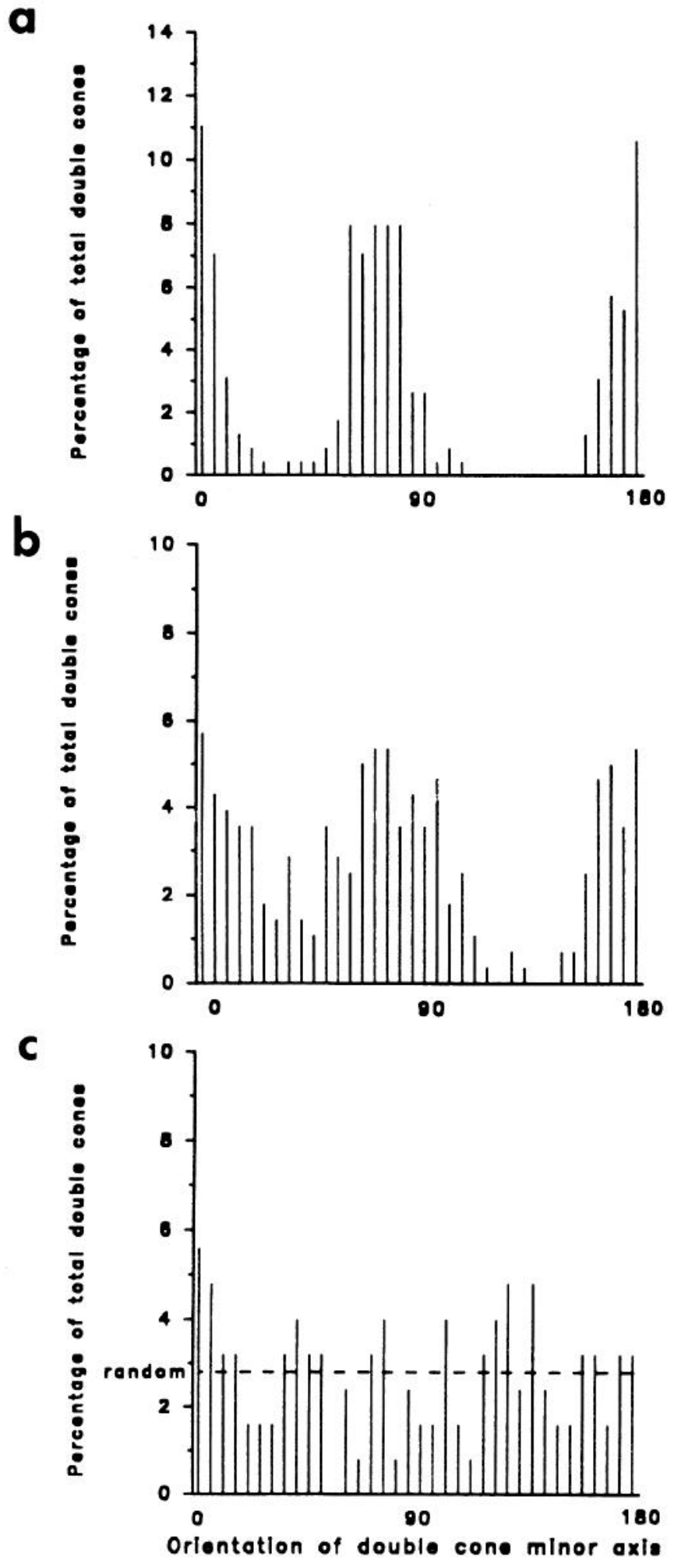

Figure 11. Orientations of double-cone minor axes within three local regions $\left(20,000-50,000 \mu \mathrm{m}^{2}\right)$ of unoperated $(a ; n=226 \mathrm{DCs})$, stretched $(b ; n=279 \mathrm{DCs})$, and regenerated retina ( $c ; n=125 \mathrm{DCs})$. The data have been slid horizontally so that one modal value of each distribution is centered at $0^{\circ}$. Bin width $=5^{\circ}$. The dotted line in $c$ indicates the expected distribution of DC orientations if they were randomly oriented.
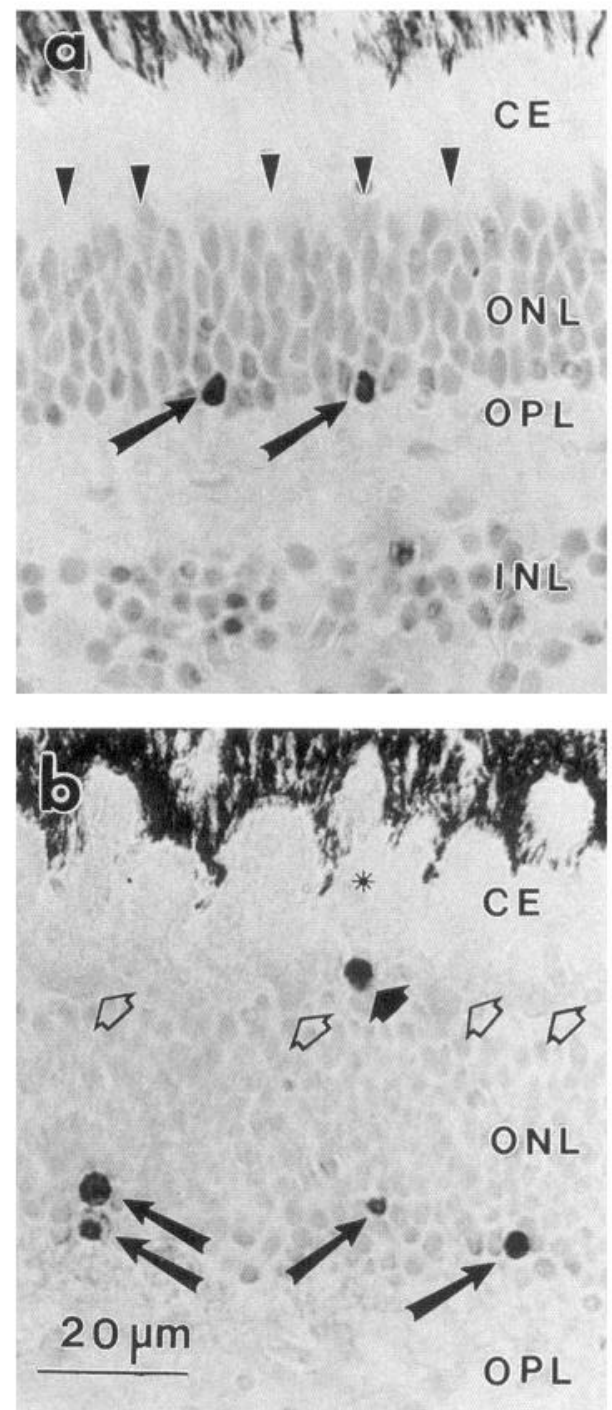

Figure 12. BrdU-positive cone nuclei in outer retina outside a lesion site. BrdU was injected $14 \mathrm{~d}$ after surgery, and the fish sacrificed $49 \mathrm{~d}$ later. $a$, The BrdU-positive nuclei (dark cells, thin arrows) in the ONL of unoperated eyes are restricted, for the most part, to the region adjacent to the outer plexiform layer $(O P L)$. These nuclei are likely to be rods. Arrowheads indicate the outer limiting membrane $(O L M) . b$, A BrdU-positive cone nucleus (solid thick arrow) is present approximately $300 \mu \mathrm{m}$ from the lesion site. BrdU-negative cone nuclei are indicated (open thick arrows). Note the different location of the cone nuclei compared to the other nearby BrdU-positive nuclei (solid thin arrows), likely to be rods. Asterisk indicates the cone ellipsoid immediately overlying the BrdU-positive cone nucleus. $P E$, Pigmented epithelium; $C E$, cone ellipsoids.

duction and local hyperplasia). Thus, the trigger for the anomalous cone generation in stretched retina was likely to be the stretch itself.

By what mechanism could stretch affect cone genesis? It might have increased the availability of some factor(s) that promotes cone production; diffusible rod-promotive factors have been inferred (Altshuler and Cepko, 1992; Hicks and Courtois, 1992; Watanabe and Raff, 1992), as have cone-promotive extracellular matrix molecules (Hewitt et al., 1990; Hunter et al., 1992). A role for such cone-promotive factors in the anomalous cone production in stretched retina cannot be ruled out, yet we 

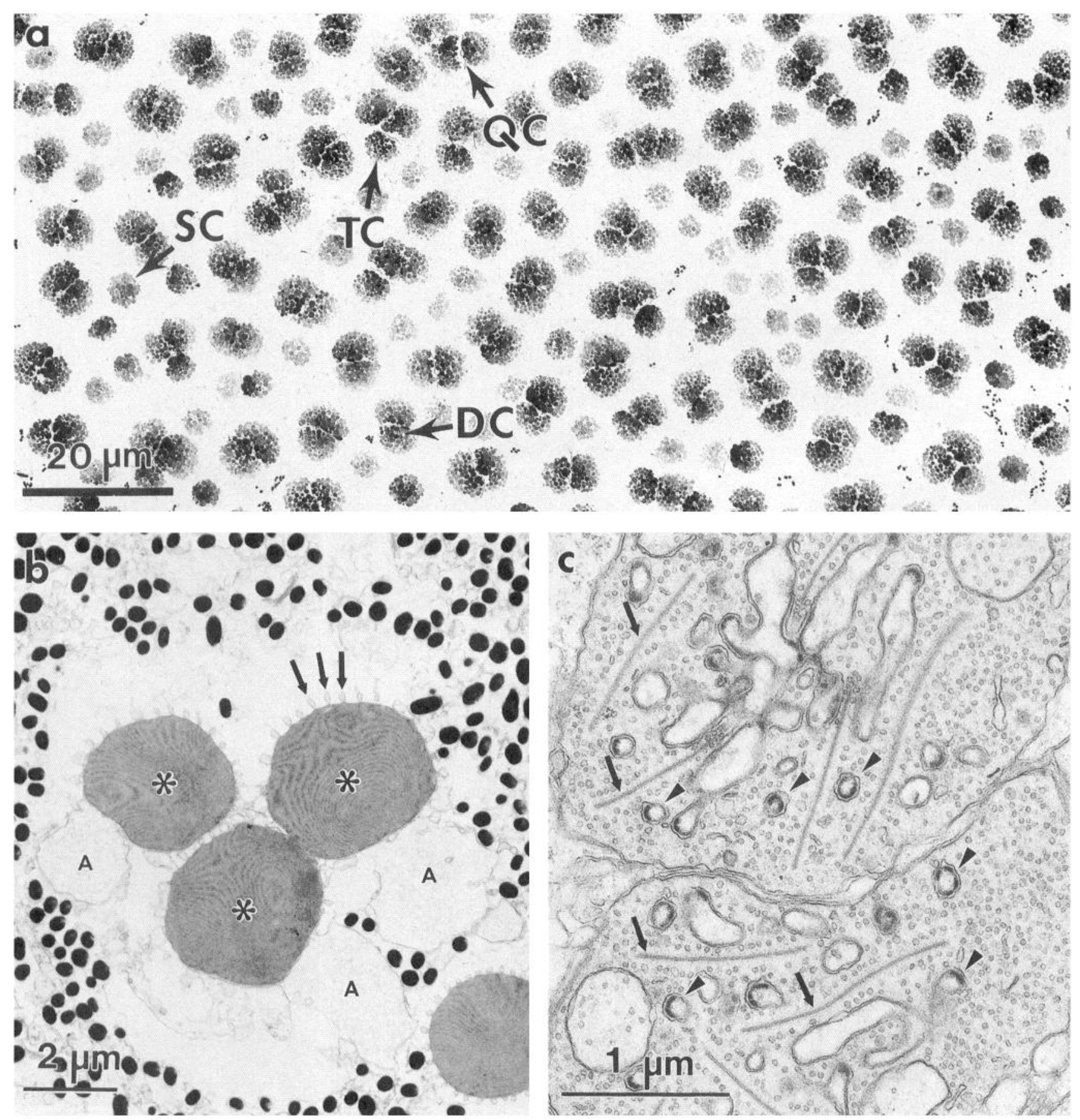

Figure 13. Electron micrographs of the cones in regenerated retina, $198 \mathrm{~d}$ after surgery. $a$, Cone mosaic revealing single cones (SC), double cones $(D C)$, triple cones $(T C)$, and quadruple cones $(Q C)$ in a disordered pattern. $b$, Outer segments of a TC (asterisks), each with an accessory outer segment $(A)$ and calical processes (arrows). Dark ovoid elements are melanin granules of the pigmented epithelium. $c$, Two cone synaptic pedicles, each with multiple synaptic ribbons (arrows), invaginating processes with electron dense material (arrowheads), and synaptic vesicles.

favor an alternative model: reduction in cellular density released a local inhibition to cone production. This is similar to the suggestions by Wigglesworth (1940) and Doe et al. (1985). Both of these reports dealt with the ontogenetic onset of widely spaced specialized cells in the insect integument. The initial epithelium was comprised of developmentally equivalent cells, and when one of them differentiated (e.g., into a neuroblast; Doe et al., 1985), it inhibited its neighbors from doing the same. This inhibition decremented laterally, and at a distance where it had dropped below some critical value, another neuroblast could develop. We extend this model to the retina, and propose that the commitment to a cone fate is subject to analogous lateral inhibition. In the normal central retina, cones are in sufficiently high density that uncommitted cells are inhibited from becoming cones. But the first phase of healing, the abrupt nonproliferative collapse of surrounding retina into the wound, reduces the planimetric density of cones, and causes some of the uncommitted cells to be "disinhibited," and they become cones. 
The new cones in stretched retina apparently represented a compensatory neurogenesis, in that they compensated for the reduced cone density, and ensured that the retinal lawn was largely free of "holes" in the cone mosaic. Their anatomy indicated that they were functional: they had an outer segment and a pedicle that made apparently normal synaptic contacts with second-order cells. This result indicated that compensatory cone neurogenesis in stretched retina was likely to be physiologically adaptive: it would restore, at least partially, visual function lost due to the stretch-induced decrease in cone density.

As fish grow, their retinas passively expand in a balloon-like manner (Ali, 1964; Johns and Easter, 1977). Does the concomitant decrease in cone planimetric density (e.g., Cameron, 1994) break cone-cone contacts, and if so, why is there no insertion of cones in adult central retina? Two morphological features of the cone mosaic are consistent with cone-cone contacts (such as those presented in Rowe et al., 1994) being maintained throughout life. First, the relative dimensions of the crystallinelattice template of the green sunfish cone mosaic (Fig. 6 of Cameron and Easter, 1993) are independent of fish size, and second, the cross-sectional area of cones increases with fish size (Cameron, unpublished observations). The coupling of cone area expansion with mosaic pattern maintenance suggests that conecone contacts are not pulled apart as the retina passively expands throughout life.

The ability to produce new functional neurons and to insert them into an adult CNS could be of obvious clinical value. As mentioned above, a neuronal insertion of this type is already known to occur naturally in adult fish, wherein rods are constantly inserted into the growing retina. Neurons have also been inserted, apparently with maintenance of function, into mammalian brains, including rat superior colliculus (Lund and Hauschka, 1976; Klassen and Lund, 1987), mutant mouse cerebellum (Sotelo and Alvarado-Mallart, 1987), and lesioned mouse neocortex (Macklis, 1993). These new neurons were all transplanted into the host from a donor, and the hosts were (except for the cerebellum studies) always neonatal. Our results differ in the important aspect that all the new neurons originated from the CNS into which they were inserted.

There are few examples of naturally occurring neuronal addition to mature nervous systems, and in these the factors that control neurogenesis probably do not include stretch: in the nuclci that control vocal behavior in canary brains, seasonal/hormonal factors appear to regulate the insertion of new neurons (Goldman and Nottebohm, 1983; Paton and Nottebohm, 1984); in the mammalian olfactory epithelium, cell loss (perhaps caused by toxic odorants) triggers the insertion of new receptor cells (Graziadei and Graziadei, 1983); in fish tectum, incoming retinal fibers stimulate the generation of new tectal neurons (Raymond et al., 1983). In the adult mouse brain, stem cells have been identified that can produce neurons in vitro (Reynolds and Weiss, 1992), and in vivo (Lois and Alvarez-Buylla, 1994). The purpose of these proliferative cells might be to compensate for neuronal loss. If so, then the cell density-dependent mechanisms that triggered anomalous cone production in stretched retina might also be involved in neurogenesis in the mammalian brain.

\section{Differentiation}

Our results demonstrated that the anomalous compound cones (ADCs, TCs, and QCs) in stretched retina were hybrids, produced by cone-cone interactions. The formation of hybrid morphologies was surprising, as it implied that these interactions occurred across generations; that is, between old (preexisting) and young cones. These interactions were reciprocal in the sense that both old and young cones influenced, and were influenced by, the other(s) that thcy contacted. For example, a preexisting $\mathrm{SC}$, with its circular cross section and radially symmetrical distribution of mitochondria (densest centrally) is changed after contacting a new cone. Its cross section flattens on one side, its mitochondria shift so that the densest mitochondria are apposed to the junction with the new cone, and it develops a subjunctional cisterna. The new cone cell acquires a morphology that is mirror-synmetric to the former SC, and both now appear to be hemi-DCs. Similarly, the two members of preexisting DCs, hemiellipsoidal in cross section, assume a novel wedge shape when contacted by a new cone to form a TC, and the new cone cell is influenced to adopt a wedge shape. In the absence of contact, an SC was produced. The presence of outer segments and synaptic pedicles (Fig. 10c) associated with ADCs and TCs indicated that the new cone cells were probably functional. Others have argued that physical contact between cells determines the primary choice of a photoreceptor fate (Adler and Hatlee, 1989; Adler, 1993). Our results extend this hypothesis by demonstrating that fish cones, independent of their age, adopt a morphological phenotype based upon physical contact, or lack thereof, with their neighbors.

Two alternatives to the hybrid hypothesis were also considered. The first is that the new cones (mostly SCs) arose from the fission of preexisting DCs. If some were to have split, their numbers would be predicted to have decreased, but the number of DCs per spoke length in stretched retina lateral to the lesion was unchanged. Moreover, the total number of cones per rhombus increased, which required that some new cones be produced. Therefore, fission of preexisting elements can be excluded as a significant source of the new cones. The second alternative is that all (as opposed to one) of the members of anomalous compound cones were new cone cells. This explanation requires cone death; for example, a DC must die in order for a TC composed of three new cone cells to take its place in the mosaic. This explanation can be excluded because at all times examined (see the abscissa of Fig. $6 f$ ) the cone mosaics were complete: we did not detect the absence of any cones.

Why are TCs and QCs present only in stretched and regenerated retina? The answer is likely to involve cone spacing. As mentioned in the previous section, in normal central retina, the cones are close enough to one another to inhibit the formation of new cones. In stretched retina, cone production was disinhibited, and new cones were inserted into the small spaces between the preexisting cones. Depending upon exactly where in the mosaic the new cones were inserted, they became $\mathrm{SCs}$, or parts of DCs, TCs, or QCs. In the case of the regenerated patch, the planimetric density of cones was abnormally high, and this produced, presumably at random, a high number of contacts between three and four cones that went on to become. TCs and QCs, respectively.

The morphological phenotypes of the sunfish cones are thus subject to change at any time, even years after their terminal mitosis. This prolonged photoreceptor plasticity is consistent with earlier work on other fish species. The chromophoric group associated with opsin can be changed by season (rudd, Scardinius erythropthalmus; Dartnall et al., 1961; Loew and Dartnall, 1976), water temperature (rainbow trout, Oncorhyncus mykiss; Tsin and Beatty, 1977), hormones (Beatty, 1972), or habitat (eel, Anguilla anguilla; Carlisle and Denton, 1959). Changes in opsin 
expression accompany changes in habitat/diet in the pollack (Pollachius pollachius; Shand et al., 1988). Some of the changes in the cone mosaic pattern during metamorphosis of the winter flounder (Iseudopleuronectes americanus) have becn attributcd to fusions of pre-existing SCs into DCs, with a concomitant change in their opsin expression (Evans and Fernald, 1993; Evans et al., 1993).

\section{Pattern formation}

The cone mosaic in normal retina is highly ordered; the DCs and SCs occupy the sides and centers, respectively, of rhombic elements that tile the retina. What makes the DCs and SCs occupy their particular locations? What makes the DCs and SCs acquire their particular morphologies? We believe that our results strongly indicate that these two questions have different, independent answers. In this section we attempt to use the results from our experiments to infer the processes that control cone mosaic pattern formation during normal growth at the marginal germinal zone.

We suggest a two-step model. The first is the formation of a protomosaic of generic cones. (The protomosaic is a two-dimensional array of cells that presages the mature cone mosaic, and a generic cone is a cell committed to becoming a cone, but whose particular phenotype has yet to be determined.) Each generation of new cones must space out in such a way that the protomosaic forms, with individual generic cones alternating with pairs, and this protomosaic spreads out to form the new retina. The second step is the formation of DCs (through contactmediated interactions with an adjacent generic cone) and SCs (from generic cones that do not contact any neighbors). Thus, the determinative step is the commitment to become a cone, and the particular morphological subtype (SC or DC) then depends upon contact with another cone.

We do not have any information on the events contributing to the formation of the protomosaic, but we suggest that long-range lateral inhibitory interactions (Wigglesworth, 1940; Doe et al., 1985) between members of a cellular equivalence group could produce appropriate spacing. The intercellular interactions that produce DCs are also unknown, but are likely to include shortrange intercellular signalling akin to that involved in the determination of the different cell types in the Drosophila ommatidium (Tomlinson and Ready, 1987; Banerjee and Zipursky, 1990). Walls (1942) suggested that DCs formed during normal development are composed of sibling pairs, but Scholes (1976) argued otherwise. Our results indicated that DCs-and all other compound cone types - can be composed of nonsiblings, and therefore support Scholes' view.

The cone protomosaic at the marginal germinal zone gives rise to a very orderly mosaic in central retina (Lyall, 1957; Cameron and Easter, 1993). The mechanisms that control this spatial organization are unknown, but we suggest three possibilities: interactions between young and old retina, an intrinsic property of the marginal germinal zone, or an influence from an extraretinal source, such as the pigmented epithelium. Only the first of these possibilities has been supported empirically, although not with direct respect to formation of the cone mosaic's twodimensional pattern (Kock and Reuter, 1978; Hitchcock and Easter, 1986; Reh and Tully, 1986; Reh, 1987; Wikler and Rakic, 1991). The lack of order in the regenerated cone mosaic suggests an absence or degradation of this mechanism, whatever it may be. For example, the forces that spatially register regenerated and older retina may have to work over longer distances than usual because of the surrounding stretch, and are thus unable to organize a normal mosaic pattern in the regenerated patch.

\section{Summary and conclusions}

We have described the morphological phenotypes and mosaic patterns of regenerated cone photoreceptors in the adult green sunfish retina. The major results of this report are (1) the demonstration of a novel, adaptive compensatory neurogenesis in the adult vertebrate CNS: new cone photoreceptors were interstitially regenerated in stretched, but intact, adult retina from proliferative precursors; (2) both adult and newly born cones had their morphological phenotypes modified by contact with other cones; and (3) a small patch of regenerated retina does not reestablish a normal cone photoreceptor mosaic pattern. We have used these results to construct a two-step model to account for the origin of the highly organized cone photoreceptor mosaic, and to suggest a possible mechanism for the induction of neurogenesis in the adult CNS.

\section{References}

Adler R (1993) Determination of cellular types in the retina. Invest Ophthalmol Vis Sci 34:1677-1682.

Adler R, Hatlee M (1989) Plasticity and differentiation of embryonic retinal cells after terminal mitosis. Science 243:391-393.

Ali MA (1964) Stretching of the retina during growth of the salmon (Salmo salar). Growth 28:83-98.

Altshuler D, Cepko C (1992) A temporally regulated, diffusible activity is required for rod photoreceptor development in vitro. Development 1 14:947-957.

Banerjee U, Zipursky SL (1990) The role of cell-cell interaction in the development of the Drosophila visual system. Neuron 4:177-187.

Beatty DD (1972) Visual pigment changes in salmonid fishes in response to exogenous L-thyroxine, bovine TSH and 3-dehydroretinol. Vision Res 12:1947-1960.

Bereiter-Hahn J (1986) Epidermal cell migration and wound repair. In: Biology of the integument (Bereiter-Hahn J, Matoltag AG, Richards KS, eds), pp 443-471. New York: Springer.

Berger ER (1967) Subsurface membranes in paired cones of adult and neonatal Lebistes retinae. J Ultrastruct Res 17:220-232.

Bernhardt R, Easter SS Jr (1988) Regenerated optic fibers in goldfish reestablish a crude sectoral order in the visual pathway. J Comp Neurol 277:403-419.

Borwein B, Hollenberg MJ (1973) The photoreceptors of the "foureyed" fish, Anableps anableps L. J Morphol 140:405-442.

Burnside B, Nagle B (1983) Retinomotor movements of photoreceptors and retinal pigment epithelium: mechanisms and regulation. In: Progress in retinal research (Osborn N, Chader G, eds), pp 67-109. New York: Pergamon.

Cameron DA (1995) Asymmetric retinal growth in the adult teleost green sunfish (Lepomis cyanellus). Vis Neurosci, in press.

Cameron DA, Easter SS Jr (1993) The cone photoreceptor mosaic of the green sunfish, Lepomis cyanellus. Vis Neurosci 10:375-384.

Cantino D, Marchiafava PL, Strettoi E, Strobbia E (1986) Subsurface cisternae in retinal double cones. J Submicrosc Cytol 18:559-566.

Carlisle DB, Denton EJ (1959) On the metamorphosis of the visual pigments of Anguilla anguilla L. J Mar Biol Assoc UK 38:97-102.

Dartnall HJA, Lander MR, Munz FW (1961) Periodic changes in the visual pigments of a fish. In: Progress in photobiology (Christensen B, Buchmann B, eds), pp 203-213. Amsterdam: Elscvicr.

Dearry A, Barlow RB Jr (1987) Circadian rhythms in the green sunfish retina. J Gen Physiol 89:745-770.

Doe CQ, Kuwada JY, Goodman CS (1985) From epithelium to neuroblasts to neurons: the role of cell interactions and cell lineage during insect neurogenesis. Philos Trans R Soc Lond [Biol] 312:67-81.

Easter SS Jr (1992) Retinal growth in foveated teleosts: nasotemporal asymmetry keeps the fovea in temporal retina. J Neurosci 12:23812392.

Evans BI, Fernald RD (1993) Retinal transformation at metamorphosis in the winter flounder (Pseudopleuronectes americanus). Vis Neurosci 10:1055-1064.

Evans BI, Hárosi FI, Fernald RD (1993) Photoreceptor spectral absor- 
bance in larval and adult winter flounder (Pseudopleuronectes americanus). Vis Neurosci 10:1065-1071.

Godement P, Vanselow J, Thanos S, Bonhoeffer F (1987) A study in developing visual systems with a new method of staining neurones and their processes in fixed tissue. Development 101:697-713.

Goldman SA, Nottebohm FN (1983) Neuronal production, migration, and differentiation in a vocal control nucleus of the adult female canary brain. Proc Natl Acad Sci USA 80:2390-2394.

Graziadei PP, Monti Graziadei AG (1983) Regeneration in the olfactory system of vertebrates. Am J Otolaryngol 4:228-233.

Hewitt AT, Lindsey JD, Carbott D, Adler R (1990) Photoreceptor survival-promoting activity in interphotoreceptor matrix preparations: characterization and partial purification. Exp Eye Res 50:79-88.

Hicks D, Courtois Y (1992) Fibroblast growth factor stimulates photoreceptor differentiation in vitro. J Neurosci 12:2022-2033.

Hitchcock PF, Easter SS Jr (1986) Retinal ganglion cells in goldfish: a qualitative classification into four morphological types, and a quantitative study of the development of one of them. J Neurosci 6:10371050 .

Hitchcock PF, VanDeRyt JT (1994) Regeneration of the dopamine-cell mosaic in the retina of the goldfish. Vis Neurosci 10:209-218.

Hitchcock PF, Lindsey Myrh KJ, Easter SS Jr, Mangione-Smith R, Dwyer Jones D (1992) Local regeneration in the retina of the goldfish. I Neurnhiol 23:187-203.

Honig MG, Hume RI (1986) Fluorescent carbocyanine dyes allow living neurons of identified origin to be studied in long-term cultures. J Cell Biol 103:171 187

Hunter DD, Murphy MD, Olsson CV, Brunken WJ (1992) S-laminin expression in adult and developing retinae: a potential cue for photoreceptor norphogenesis. Neuron 8:399-413.

Johns PR (1982) Formation of photoreceptors in larval and adult goldfish. J Neurosci 2:178-198.

Johns PR, Easter SS Jr (1977) Growth of the adult goldfish eye. II Increase in retinal cell number. J Comp Neurol 176:331-342.

Johns PR, Fernald RD (1981) Genesis of rods in teleost fish retina. Nature 293:141-142.

Klassen H, Lund RD (1987) Retinal transplants can drive a pupillary reflex in host rat brains. Proc Natl Acad Sci USA 84:6958-6960.

Kock J-H, Reuter T (1978) Retinal ganglion cells in the crucian carp (Carassius carassius). II. Overlap, shape, and tangential orientation of dendritic trees. J Comp Neurol 179:549 568.

Kumar V, Cotran RS, Robbins SL (1992) Repair: Cell growth, regeneration and wound healing. In: Basic pathology, pp 47-60. Philadelphia: Saunders.

Loew ER, Dartnall HJA (1976) Vitamin $A_{1} / A_{2}$-based visual pigment mixtures in cones of the rudd. Vision Res 16:891-896.

Lois C, Alvarez-Buylla A (1994) Long-distance neuronal migration in the adult mammalian brain. Science 264:1145-1148.

Lombardo F (1972) Andamento e localizzazione delle mitosi durante la rigenerazione della retina di un Teleosteo adulto. Lincei-Rendiconti Sci Fis Mat Nat 53:323-327.

Lund RD, Hauschka SD (1976) Transplanted neural tissue develops connections with host rat brain. Science 193:582-584.

Lyall AH (1957) Cone arrangements in teleost retinae. Q J Microsc Sci 98:189-201.

MacDonald RE, Hitchcock PF, Wilson SW, VanDeRyt JT (1994) Pax6 gene expression in the developing and regenerating retina of teleost fish. Invest Ophthalmol Vis Sci [Suppl] 35:1404.

Macklis JD (1993) Transplanted neocortical neurons migrate selectively into regions of neuronal degeneration produced by chromophoretargeted laser photolysis. J Neurosci 13:3848-3863.

Maier W, Wolburg H (1979) Regeneration of the goldfish retina after exposure to different doses of ouabain. Cell Tissue Res 202:99-118.
Martin P, Lewis J (1992) Actin cables and epidermal movement in embryonic wound healing. Nature 360:179-182.

Matthey R (1926) Récupération de la vue après greffe de l'oeil chez le Triton adulte. C R Soc Biol 94:4-5.

Mensinger AF, Powers MK (1993) Visual function following surgical removal of retinal tissue. Invest Ophthalmol Vis Sci [Suppl] 34:1176.

Paton JA, Nottebohm FN (1984) Neurons generated in the adult brain are recruited into functional circuits. Science 225:1046-1048.

Powers MK, Raymond PA (1990) Development of the visual system. In: The visual system of fish (Douglas RH, Djamgoz MBA, eds), pp 419-442. London: Chapman and Hall.

Raymond PA (1985) The unique origin of rod photoreceptors in the telcost retina. Trends Neurosci 8:12-17.

Raymond PA, Rivlin PK (1987) Germinal cells in the goldfish retina that produce rod photoreceptors. Dev Biol 122:120-138.

Raymond PA, Easter SS Jr, Burnham JA, Powers MK (1983) Postembryonic growth of the optic tectum in goldfish. II. Modulation of cell proliferation by retinal fiber input. J Neurosci 3:1092-1099.

Raymond PA, Reifler MJ, Rivlin PK (1988) Regeneration of goldfish retina: rod precursors are a likely source of regenerating cells. J Neurobiol 19:431-463.

Reh TA (1987) Cell-specific regulation of neuronal production in the larval frog retina. J Neurosci 7:3317-3324.

Reh TA, Tully TT (1986) Regulation of tyrosine hydroxylase-containing amacrine cell number in larval frog retina. Dev Biol 114:463469.

Reh TA, Nagy T, Grctton H (1987) Retinal pigmented epithelial cells induced to transdifferentiate to neurons by laminin. Nature 330:6871.

Reynolds BA, Weiss S (1992) Generation of neurons and astrocytes from isolated cells of the adult mammalian central nervous system. Science 255:1707-1710.

Rowe MP, Engheta N, Easter SS Jr, Pugh EN Jr (1994) Graded-index model of a fish double cone exhibits differential polarization sensitivity. J Opt Soc Am A 11:55-70.

Scholes JH (1976) Neuronal connections and cellular arrangement in the fish retina. In: Neural principles in vision (Zettler F, Weiler R, eds), pp 63-93. Berlin: Springer.

Shand J, Partridge JC, Archer SN, Potts GW, Lythgoe JN (1988) Spectral absorbance changes in the violet/blue sensitive cones of the juvenile pollack, Pollachius pollachius. J Comp Physiol A 163:699703.

Sotelo C, Alvarado-Mallart RM (1987) Embryonic and adult neurons interact to allow Purkinje cell replacement in mutant cerebellum. Nature 327:421-423.

Sperry RW (1949) Reimplantation of eyes in fishes (Bathygobius soporator) with recovery of vision. Soc Exp Biol Med Proc 71:80-81.

Stone LS (1950) Neural retina degeneration followed by regeneration from surviving retinal pigment cells in grafted adult salamander eyes. Anat Rec 106:89-110.

Tomlinson A, Ready DF (1987) Neuronal differentiation in the Drosophila ommatidium. Dev Riol 120:366-376.

Tsin AT, Beatty DD (1977) Visual pigment changes in rainbow trout in response to temperature. Science 195:1358-1360.

Walls GL (1942) The vertebrate eye and its adaptive radiation. Ncw York: Hafner.

Watanabe T, Raff MC (1992) Diffusible rod-promoting signals in the developing rat retina. Development 1 14:899-906.

Wigglesworth VB (1940) Local and general factors in the development of pattern in Rhodnius prolixus. J Exp Biol 17:180-200.

Wikler KC, Rakic P (1991) Relation of an array of early-differentiating cones to the photoreceptor mosaic in the primate retina. Nature 351: $397-400$. 